\title{
Boiling Heat Transfer and Two-Phase Pressure Drops within Compact Plate Heat Exchangers: Experiments and Flow Visualizations
}

Valentin Solotych ${ }^{\mathrm{a}}$, Donghyeon Lee ${ }^{\mathrm{a}}$, Jungho Kim ${ }^{\mathrm{a}, *}$, Raffaele L. Amalfi ${ }^{\mathrm{b}}$, John R. Thome ${ }^{\mathrm{b}}$

aDepartment of Mechanical Engineering, University of Maryland, College Park, Maryland, USA

${ }^{\text {b}}$ Laboratory of Heat and Mass Transfer, École Polytechnique Fédérale de Lausanne, Switzerland

*Corresponding author: Tel. 301-405-5437; fax: 301-314-9477

E-mail address: kimjh@umd.edu (J. Kim)

\begin{abstract}
Infrared (IR) thermography was used to measure the local heat transfer coefficients within two plate heat exchanger geometries. The chevron patterns were machined into polycarbonate and IR transparent calcium fluoride plates, both of which were electrically heated using flexible film heaters at heat fluxes up to $0.8 \mathrm{~W} \mathrm{~cm}^{-2}$. The test fluid was a refrigerant (HFE7100) at mass fluxes between 25 and $100 \mathrm{~kg} \mathrm{~m}^{-2} \mathrm{~s}^{-1}$, and qualities from 0 to 0.9 . The apparatus and data reduction technique were validated by comparing the single-phase heat transfer and pressure drop data against the prediction methods from the literature. Adiabatic flow visualizations were conducted to link the flow patterns with the observed heat transfer. The frictional pressure gradient and heat transfer coefficient were compared with available correlations. It was shown that the heat transfer coefficient and the frictional pressure gradient increased with mass flux and quality. The comparison indicated the need for new prediction methods for predicting the local thermalhydraulic performance over a wide range of operating conditions.
\end{abstract}

Keywords: Two-phase, evaporation, adiabatic flow visualization, chevron plate heat exchangers, infrared measurements, local heat transfer coefficient, flow regimes, HFE7100. 


\begin{tabular}{|c|c|c|c|}
\hline \multicolumn{4}{|c|}{ Nomenclature } \\
\hline A & abbreviation for the plate corrugation & $\varepsilon$ & emissivity \\
\hline$a$ & amplitude of the corrugation (m) & $\varphi$ & surface enlargement factor \\
\hline $\mathrm{B}$ & abbreviation for the chevron angle & $\lambda$ & wavelength of the corrugation (m) \\
\hline$b$ & corrugation pressing depth $(\mathrm{m})$ & $\rho$ & density $\left(\mathrm{kg} \mathrm{m}^{-3}\right)$ \\
\hline$c_{p}$ & specific heat $\left(\mathrm{J} \mathrm{kg}^{-1} \mathrm{~K}^{-1}\right)$ & $\mu$ & dynamic viscosity $(\mathrm{Pa} \cdot \mathrm{s})$ \\
\hline$D_{p}$ & distance between two pressure taps (m) & r & Array of values for MAE \\
\hline$d$ & diameter $(m)$ & & \\
\hline$f$ & Fanning friction factor & & Subscript \\
\hline$g$ & gravitational constant, $\mathrm{g}=9.81\left(\mathrm{~m} \mathrm{~s}^{-2}\right)$ & $a$ & acceleration \\
\hline$H$ & specific enthalpy $\left(\mathrm{J} \mathrm{kg}^{-1}\right)$ & $e$ & equivalent \\
\hline$h$ & heat transfer coefficient $\left(\mathrm{W} \mathrm{m}^{-2} \mathrm{~K}^{-1}\right)$ & $\exp$ & experimental \\
\hline$k$ & thermal conductivity $\left(\mathrm{W} \mathrm{m} \mathrm{m}^{-1} \mathrm{~K}^{-1}\right)$ & $f$ & frictional \\
\hline $\mathrm{L}$ & abbreviation for corrugation pitch & $g$ & gravitational \\
\hline$L_{P}$ & length of the $\mathrm{CaF}_{2}$ plate $(\mathrm{m})$ & $h$ & hydraulic \\
\hline$N u$ & Nusselt number, $N u=h d_{h} / k$ & $i$ & inlet \\
\hline$M A E$ & mean absolute error & $l$ & liquid \\
\hline$\dot{m}$ & mass rate $\left(\mathrm{kg} \mathrm{s}^{-1}\right)$ & $l v$ & liquid to vapor \\
\hline$n$ & number of data points & $m$ & mean \\
\hline$P$ & pressure $(\mathrm{Pa})$ & meas & measured \\
\hline$q ”$ & heat flux & $o$ & outlet \\
\hline$\dot{Q}$ & power supplied to the preheater/PHE (W) & pre & predicted \\
\hline$R e$ & Reynolds number, $\operatorname{Re}=G d_{h} / \mu$ & sat & saturation state \\
\hline$s$ & path length along the corrugation (m) & tot & total \\
\hline$T$ & temperature $(\mathrm{K})$ & $v$ & vapor \\
\hline$W_{P}$ & width of the $\mathrm{CaF}_{2}$ plate $(\mathrm{m})$ & & \\
\hline$x$ & quality & & Acronyms \\
\hline$X, Y, Z$ & coordinates $(\mathrm{m})$ & HTC & heat transfer coefficient \\
\hline & & $\mathrm{CaF}_{2}$ & calcium fluoride \\
\hline & Greek & PHE & plate heat exchanger \\
\hline$\beta$ & chevron angle $\left(^{\circ}\right)$ & $\mathrm{TC}$ & thermocouple \\
\hline$\gamma$ & corrugation aspect ratio & & \\
\hline
\end{tabular}




\section{Introduction and literature survey}

Corrugated plate heat exchangers (PHEs) provide a very compact and efficient method to exchange heat between two fluids. They are highly flexible and easy to disassemble, an advantage for applications where it is required to clean the heat exchanger frequently (e.g. gasketed PHE). PHEs can be optimized by varying geometric parameters to achieve the desired performance, such as length, width, corrugation geometry, number of plates, and flow arrangement. PHEs are widely applied in two-phase evaporation services where the shear stress between liquid and vapor can induce more turbulence and produce thinner boundary layers.

The geometry of the PHE corrugation pattern is typically characterized by the wavelength of the surface corrugation $(\lambda)$, amplitude of the surface corrugation $(a)$, and corrugation chevron angle $(\beta)$. The nomenclature used in this paper to characterize the corrugation patterns is shown in Fig. 1.

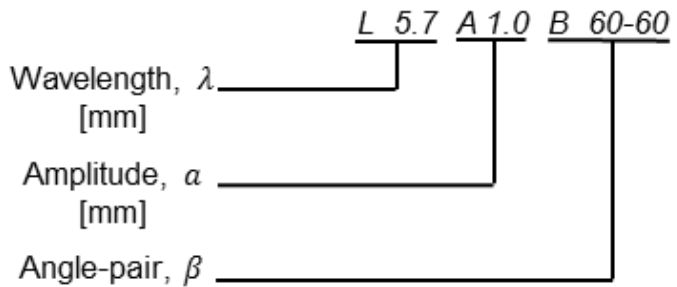

[?]

L5.7A1.0B60-60

L3.7A0.5B65-65

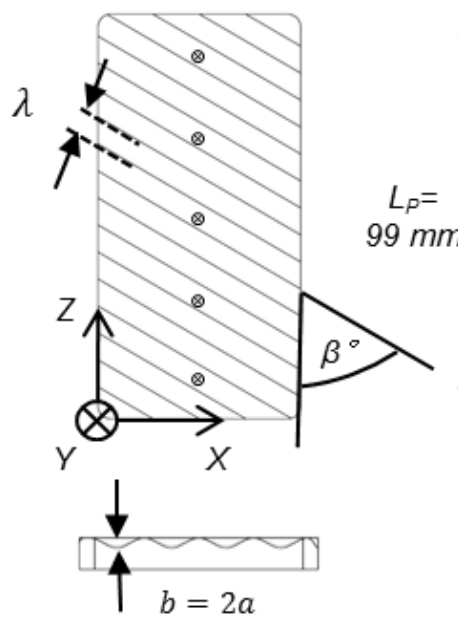

(a)

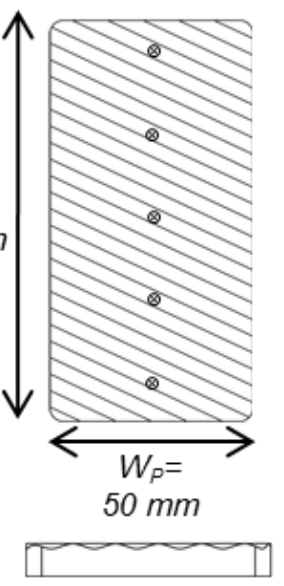

(b)

Fig. 1. Schematic of the two plate geometries tested in this study and the location of the thermocouples: (a) test section L5.7A1.0B60-60, (b) test section L3.7A0.5B65-65 
The wavelength and amplitude of the corrugation are indicated by $L$ and $A$ respectively. The chevron angle $B$ is followed by two numbers since PHEs can be arranged in a mixed configuration resulting in an overall angle which is the average of both plates, e.g., mixing a $60^{\circ}$ and $30^{\circ}$ plate would result in a $45^{\circ}$ arrangement. As an example of the nomenclature, the PHE L3.7A0.5B65-65 would have a corrugation wavelength of $3.7 \mathrm{~mm}$, an amplitude of $0.5 \mathrm{~mm}$, and two plates both having chevron angles of $65^{\circ}$.

A summary of relevant single-phase correlations in PHEs was given by Ayub [1] along with a correlation for two-phase applications based on a vast collection of experimental data (including R22 and ammonia as working fluids). Manglik et al. [2] provided a knowledge base for designing single- and two-phase PHEs. Khan et al. [3] developed a set of correlations for two-phase evaporators with a focus on ammonia as a working fluid that included the effect of chevron angle on the thermal and hydraulic performance. Abu-Khader [4] provided a summary of the single- and two-phase PHE research in recent years.

Only a few groups have performed local measurements in order to obtain local heat transfer coefficients (HTC) within PHEs. Gaiser and Kottke [5] and Stasiek et al. [6] used ammonia absorption and liquid crystal thermography respectively to obtain the local heat transfer in a unit cell with a resolution of $0.2 \mathrm{~mm}^{2}$. Freund and Kabelac [7] obtained a resolution of $0.5 \mathrm{~mm}^{2}$ by using temperature oscillation IR thermography within two PHE plates (L12A1.6B63-63). All of these studies were limited to single-phase flow. Quasi local measurements for PHE evaporators were conducted by Djordjevic and Kabelac [8] who used an array of thermocouples in two PHEs (L12A1.6B63-63 and L12A1.6B27-27) to measure the wall and liquid temperatures during boiling of R134a and ammonia. The overall length of the PHE was $0.8 \mathrm{~m}$, meaning they could calculate the local quality and the associated local HTC. They observed, as have other groups, that HTC was independent of the heat flux, but depends heavily on the quality. They also concluded that the HTC increases with mass flux at a given quality, but can decrease with quality at lower mass fluxes when the quality exceeds 0.5 . Finally, they compared their data to existing correlations and found that the modified Steiner and Taborek [9] and Danilova et al. [10] correlations best fit their experimental database.

Recently, Vakili-Farahani et al. [11,12] examined the local heat transfer and pressure drop within a PHE channel (L3.7A0.5B65-65, port-to-port length of $228 \mathrm{~mm}$ ) created by two plates that were electrically heated. The fluid was R245fa. The plates were pressed together by two 
PVC plates to stabilize and insulate the test section. Six windows along the length of the PHE were machined into the PVC plates allowing the outer surface temperature (and thus the local HTC) to be measured with an IR-camera. Through adiabatic two-phase flow tests, the authors were able to measure the saturation temperature of the refrigerant and thereby calculate the quasi local pressure for each window. They concluded that the two-phase behavior in PHEs is similar to pipe flow, and the flow distributions at the PHE inlet and outlet have a significant effect on the overall thermal and hydraulic performance.

Amalfi et al. [13,14] provided a comprehensive literature survey of flow boiling heat transfer and two-phase frictional pressure drops mechanisms within chevron PHEs. In this study, the prediction methods available in the open literature from 1981 until 2014 were detailed and a consolidated experimental database from 13 research studies were culled that included 3601 data points. The authors carried out a sensitivity analysis to investigate the effect of plate geometrical parameters on the thermal and hydraulic performance, and an extensive statistical comparison of all available two-phase prediction methods against the above mentioned databank was also furnished. Using dimensional analysis coupled with the multi-regression technique, new methods for predicting local HTC and local frictional pressure gradient within plate heat exchangers were developed and shown to work better than the available methods.

During the evaporation process, the heat transfer mechanisms are strongly dependent on the flow regimes. Few studies have performed two-phase visualizations in PHEs. Gradeck and Lebouché [15] used water and nitrogen to visualize horizontal flow in a PHE geometry (L20A10B60-60) machined into acrylic. The superficial liquid velocity was held constant, while the superficial gas velocity was varied. Only two distinct flow patterns were observed: stratified flow and bubbly flow.

Tribbe and Müller-Steinhagen [16,17] studied adiabatic two-phase flow using three plate geometries to create six PHEs. The authors identified five flow regimes: regular bubbly flow, irregular bubbly flow, churn flow, film flow, and partial film flow. In addition, they provided a flow pattern map for PHEs based on the liquid and vapor superficial velocities.

Vlasogiannis et al. [18] removed the end plate of a PHE and replaced it with a corrugated acrylic plate (L10A1.2B60-60) in order to investigate two-phase phenomena in a water-air flow. The variety of flow patterns were recorded using a high speed camera. Their heat transfer results showed that at low liquid superficial velocities $\left(<0.025 \mathrm{~m} \mathrm{~s}^{-1}\right)$ the liquid remained at the bottom 
of the trough and was sheared by a continuous gas phase. At higher liquid superficial velocities $\left(>0.1 \mathrm{~m} \mathrm{~s}^{-1}\right.$ ) and low air velocities a continuous liquid phase pervaded the channel. At intermediate to high superficial air and water flow velocities, a mixture of both regimes or slug flow was observed. The HTC was found to be higher with injected air compared to the normal air flow, especially at low superficial water velocities.

Hsieh et al. [19] used a L10A1.5B60-60 PHE with an acrylic plate to visualize two-phase flow of R-134a. With an increase in heat flux at a given mass flux, larger bubbles formed on the surface before departing the surface. When the heat flux was constant and the mass flux changed, the bubble size was noticeably affected. Small, discrete bubbles were observed at high subcooling, whereas bubbles would coalesce and move vigorously at lower subcooling.

Asano et al. [20] visualized the flow regimes for air/water two-phase flow within a commercial PHE using thermal neutron radiography since the plates were opaque to visible light. The liquid and air distributions were measured for a single channel as well as for a multichannel PHE from which a distribution of phases was derived. When two-phase flow was introduced into the PHE, the gas phase was observed to occupy the center of the channel while the liquid phase was in contact with the plate surfaces.

Nilpueng and Wongwises [21] adopted a visualization technique similar to Vlasogiannis et al. [18] by removing the end plate of a commercial PHE and replacing it with an identical plate fabricated in transparent polyurethane. They used a non-symmetrical plate with chevron angles of $55^{\circ}$ and $10^{\circ}$. By switching the flow direction, they were able to classify different flow patterns that were based on the inlet quality and gravity effect. For upward flow, bubble recirculation flow, bubbly flow, and annular-liquid bridge flow were observed. The annular-liquid bridge flow was a regime in which a thin water film was present over the plate surface, while the air flowed between the water films. For downward flow, the regimes observed were slug flow, annularliquid bridge/air-alone flow, and annular-liquid bridge flow.

This paper describes experimental results obtained using the IR-based technique described in Solotych et al. [22] to measure highly resolved heat transfer distribution within L5.7A1.0B6060 and L3.7A0.5B65-65 PHE cells during upward flow boiling of HFE7100. The working fluid was chosen based on its boiling point $\left(61^{\circ} \mathrm{C} @ 1\right.$ bar) which is ideal for the current setup since it is high enough to reduce ambient noise during IR measurements and low enough to avoid damaging heat sensitive components in the test section. It is a nontoxic fluid and is representative 
of other refrigerants. The L5.7A1.0B60-60 geometry is similar to commonly used PHE evaporators, whereas the L3.7A0.5B65-65 geometry is a novel configuration that minimizes refrigerant charge, is more compact, and gains higher performances by decreasing the pressing depth and corrugation wavelength. The results are compared with existing correlations for pressure drop and heat transfer. The local heat transfer results within a single representative cell and the adiabatic flow visualizations are used to link the local HTC to the flow regimes. Measurement of the local HTC distribution within the heat exchanger utilizing spatial resolution in conjunction with flow visualization allows researchers to gain insight into the mechanisms by which heat is transferred during boiling in compact heat exchangers-this will greatly facilitate the development of new, innovative, higher performance designs based on a solid understanding of the underlying physics.

\section{Experimental technique and data reduction}

The technique used to acquire single-phase local HTC along the corrugated plate was described in detail in Solotych et al. [22]. A short summary of this technique, followed by the extensions to two-phase flow and some modifications to the experimental apparatus are discussed below.

\subsection{Overview of IR measurement technique and apparatus}

Two PHE geometries (L5.7A1.0B60-60 and L3.7A0.5B65-65) were machined into calcium fluoride $\left(\mathrm{CaF}_{2}\right)$ and polycarbonate plates. A thin, flexible film heater (Dupont 200RS100) consisting of a polyimide layer containing electrically conductive carbon bound to an electrically insulating polyimide layer, was epoxied on the corrugated surfaces to act as the heating element. Silver paint was used to make low resistance contacts to the electrically conductive film. Since the heater shape required to cover the PHE surface was a parallelogram, the paint was applied to the heated film such that the generated heat flux was uniform (Fig. 2). The standard deviation of the heater temperature within the heated area was $0.003{ }^{\circ} \mathrm{C}$ when the heater temperature had risen by $0.5^{\circ} \mathrm{C}$ after the heater power was applied for $8 \mathrm{~ms}$. 


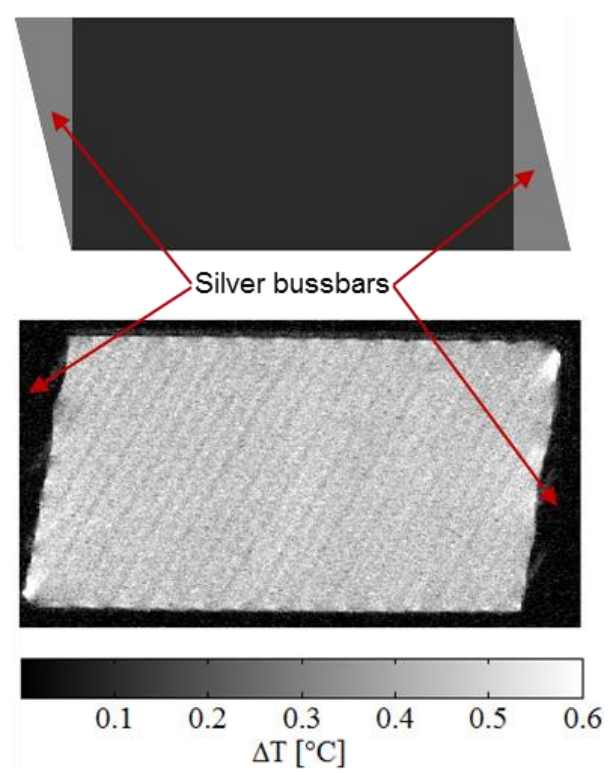

Fig. 2. Heater film shape required to cover a rectangular PHE plate along with silver bussbars shaped to provide uniform heat flux (top); the temperature distribution on the PHE surface measured by the IR camera during transient heating of the film to test the heater uniformity ( $\Delta \mathrm{T}$ is the temperature difference between the heated and unheated state after $8 \mathrm{~ms}$ of heating (bottom).

Since $\mathrm{CaF}_{2}$ is highly transparent in the IR-spectrum and the heating film is opaque and has a high emissivity $(\varepsilon>0.94)$, the temperature of the film was measured using an IR-camera by looking through the flat side of the $\mathrm{CaF}_{2}$ plate through the non-conducting polyimide to the heated surface. Since $\mathrm{CaF}_{2}$ is expensive, brittle, hard to machine, and since the surface temperature measurement was only required on one plate, it was decided to fabricate the opposing plate using polycarbonate. Five thermocouples were placed within the flow channel (Fig. 1) by drilling small holes $(0.5 \mathrm{~mm})$ into the polycarbonate plate and using epoxy to fix the tip of each thermocouple in place within the center of the flow channel. Since the polycarbonate plate had some compliance, it could be pressed onto the $\mathrm{CaF}_{2}$ to minimize any gaps between the plates at the contact points. To prevent the two heater films from shorting at the contact points, small pieces $(\sim 2 \times 2 \mathrm{~mm})$ of Scotch Magic ${ }^{\mathrm{TM}}$ tape $(60 \mu \mathrm{m})$ were attached to the heated film on the polycarbonate plate at each contact point. Finally, due to the heated surface being in direct contact with the liquid, the steady state heat losses into the substrate were of the order of $1-3 \%$ for the $\mathrm{CaF}_{2}$ plate and below $1 \%$ for the polycarbonate plate. 


\subsection{Data reduction}

The heated film produced a nominally uniform heat flux. The five thermocouples in the plate were used to calculate the local fluid temperature and the IR-camera provided the local temperature of the heated plate surface that was in direct contact with the fluid. The local HTC was then calculated by knowing the local values of fluid temperature, wall temperature, and the imposed heat flux. The imposed heat flux was adjusted depending on the inlet quality and mass flux so that the local wall temperature variations could be measured using the IR camera. The maximum heat flux that could be imposed, however, was limited by local burnout if the heat transfer variation over the surface was large, resulting in large uncertainties in some cases. The change in flow quality between the inlet and out of the test section was less than $10 \%$ for all cases studied and was usually much smaller.

A detailed description of the data reduction is given in Solotych et al. [22] where the calculation of the local HTC during single-phase flow was explained. The same technique was used in this study to obtain the local two-phase HTC. To be consistent with the recent literature, the Fanning friction factor and Nusselt number were computed according to the definition of the hydraulic diameter, $d_{h}$, as the characteristic length:

$$
d_{h}=\frac{d_{e}}{\varphi}=\frac{4 a}{\varphi}=\frac{2 b}{\varphi}
$$

where $\varphi$ is the surface enlargement factor:

$$
\varphi=\frac{\text { Effective Area }}{\text { Projected Area }}=\frac{\int_{0}^{\Lambda} \sqrt{1+\left(\frac{\gamma \pi}{2}\right)^{2} \cos \left(\frac{2 \pi}{\lambda} s\right)^{2} d s}}{\lambda}
$$

and $\gamma$ is the corrugation aspect ratio:

$$
\gamma=\frac{2 b}{\lambda}
$$

Details regarding the calculation of the local quality within the test section and the twophase pressure data are given below. Before entering the test section, the liquid was heated in the preheater to achieve the desired quality at the inlet of the test section. The total power input to the preheater was calculated from the following overall energy balance: 


$$
\dot{Q}=\dot{m} c_{p}\left(T_{s a t}-T_{i}\right)+\dot{m} x_{o} H_{l v}
$$

where $c_{p}$ was evaluated at the average of the preheater inlet and saturation temperature at the outlet of the preheater, and $H_{l v}$ was computed at the preheater outlet condition. Due to the pressure drop through the PHE, the latent heat of vaporization changed significantly from the inlet to the outlet. For this reason, $H_{l v}$ was locally evaluated instead of assuming a constant value, avoiding an error in the local quality calculation that could be as high as $7 \%$ at the smallest mass flow rate and highest heat flux tested. An energy balance over a differential element was performed to calculate the local quality and is shown in Fig. 3.

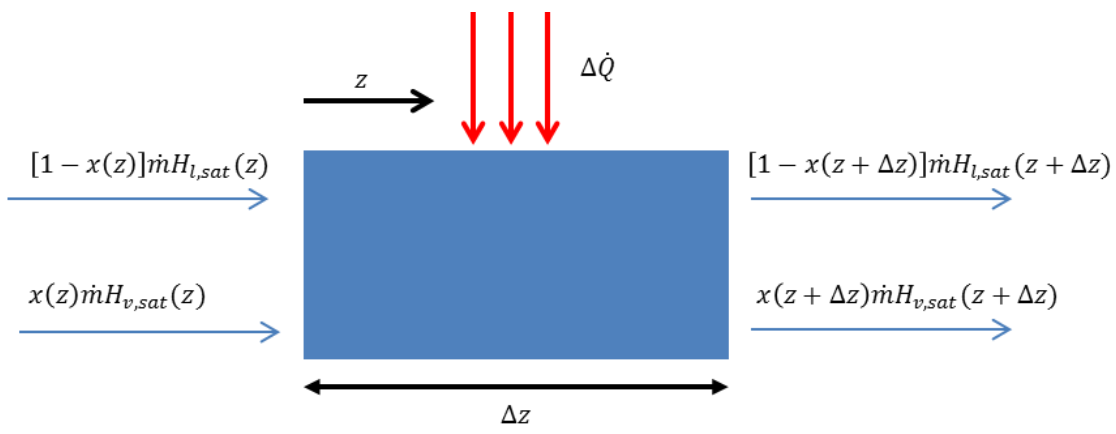

Fig. 3. Energy balance of a differential element to calculate the local quality.

Solving the above mentioned energy balance, the quality at the outlet of each differential element along the PHE length was determined as follows:

$$
x(z+\Delta z)=\frac{\left[\frac{\dot{Q}}{\dot{m}}+[1-x(z)] H_{l, s a t}(z)+x(z) H_{v, s a t}(z)-H_{l, s a t}(z+\Delta z)\right]}{H_{v, s a t}(z+\Delta z)-H_{l, s a t}(z+\Delta z)}
$$

Since the local temperature and pressure were known from the five thermocouples and five pressure taps along the PHE, the local values of the liquid and vapor enthalpy $H_{l, s a t}$ and $H_{v, \text { sat }}$ could be determined. A marching procedure was then used to calculate the local quality along the test section.

As described in Solotych et al. [22] the pressure data were obtained using an absolute pressure transducer to measure the saturation pressure close to the inlet of the PHE. A differential pressure transducer combined with four valves were used to measure the pressure 
drop along the PHE at four locations. The cross section view of the test section and the pressure measurements are given in Fig. 4.

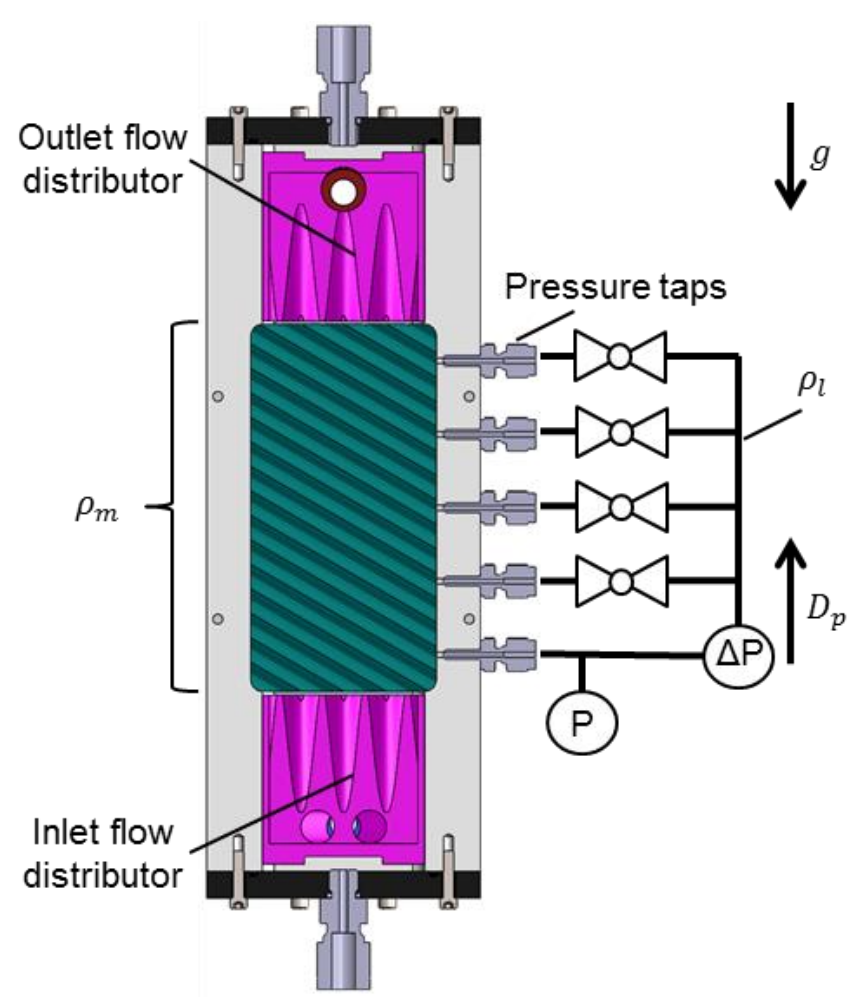

Fig. 4. Experimental setup: cross section view of the test section, including the inlet and outlet piping and the associated flow distributors, pressure taps and valve system to measure absolute and differential pressure.

The total pressure drop measured by the differential pressure transducer within the PHE was the sum of three components:

$$
\Delta P_{\text {tot, } \text { meas }}=\Delta P_{g, \text { meas }}+\Delta P_{f}+\Delta P_{a}
$$

The measured gravitational pressure drop accounted for the pressure due to the liquid head included in the differential transducer measurement:

$$
\Delta P_{g, \text { meas }}=-\left(\rho_{l} g D_{P}-g D_{P} \rho_{m}\right)
$$

which was reduced to

$$
\Delta P_{g, \text { meas }}=D_{P} g\left(\rho_{m}-\rho_{l}\right)
$$


where $D_{P}$ was the distance between two pressure taps and $\rho_{m}$ was the mean two-phase density within the PHE defined by the homogeneous model as

$$
\rho_{m}=\left[\frac{x}{\rho_{v}}+\frac{1-x}{\rho_{l}}\right]^{-1}
$$

This distance $D_{P}$ has to be accounted for since the tubes leading to the differential pressure transducer are completely filled with liquid and have a density that is different from the twophase mixture in the PHE channel. The pressure drop due to the acceleration during evaporation was estimated according to

$$
\Delta P_{a}=G^{2} \Delta x\left(\frac{1}{\rho_{v}}-\frac{1}{\rho_{l}}\right)
$$

The frictional pressure drop $\Delta P_{f}$ was computed from the above set of equations which allowed for the calculation of the actual pressure drop in the PHE

$$
\Delta P_{t o t}=\Delta P_{g}+\Delta P_{f}+\Delta P_{a}
$$

where $\Delta P_{g}$ represented the gravitational pressure drop within the PHE and was defined as:

$$
\Delta P_{g}=D_{p} g \rho_{m}
$$

The acceleration pressure drop was of the order of $0.01 \%$ of the total pressure drop and could be neglected. Hence, the pressure drop can be assumed to be linear within the PHE channel since the frictional pressure gradient was fairly constant over the short PHE length. The four differential pressure transducer measurements were used to create a linear fit to the experimental data, and the slope of the linear fit was used to determine the pressure drop. The uncertainty of the pressure drop was based on the goodness of the linear fit defined in Taylor [23].

\subsection{Test apparatus validation and uncertainty analysis}

The uncertainties of the instruments used in this work are listed in Solotych et al. [22]. The overall uncertainty (with 95\% confidence) was computed using the method of Taylor [23] and are shown by the error bars on the plots. As another check on the heat transfer measurements, an overall single-phase energy balance was performed between the energy input to the film heaters 
in the test section and the sensible heating of the liquid (measured using the inlet and outlet thermocouples, flow meter, and fluid properties). The agreement was $\pm 11 \%$ or under for all flow rates tested. The differences were likely due to heat losses to the surroundings and the measurement uncertainty, which is why they were not accounted for during data reduction.

\section{Results and discussion}

In this section, the single-phase heat transfer and pressure drop data are compared with the available correlations to validate the temperature and pressure measurements. The two-phase results are presented and the main trends of the frictional pressure gradient and local HTC are investigated. The flow boiling results are then compared against common correlations. Finally, the local heat transfer results within a single representative cell and the adiabatic flow visualizations are used to link the local HTC to the flow regimes.

\subsection{Single-phase results}

The Fanning friction factor and Nusselt number vs. Reynolds number are shown in Fig. 5. The friction factor for the L5.7A1.0B60-60 geometry was about twice that reported in Solotych et al. [22]. As stated in this paper, we could not ensure the plates were in contact with each other since both plates were fabricated from $\mathrm{CaF}_{2}$ and were somewhat imprecise. The friction factor is very sensitive to the flow area. For example, a $0.2 \mathrm{~mm}$ gap between the plates increases the flow channel area by $10 \%$ and leads to a lower pressure drop, lower liquid velocity, and lower friction factor. For the current tests, one plate was made of polycarbonate that had a small amount of flex, allowing the plates to be pressed together. 


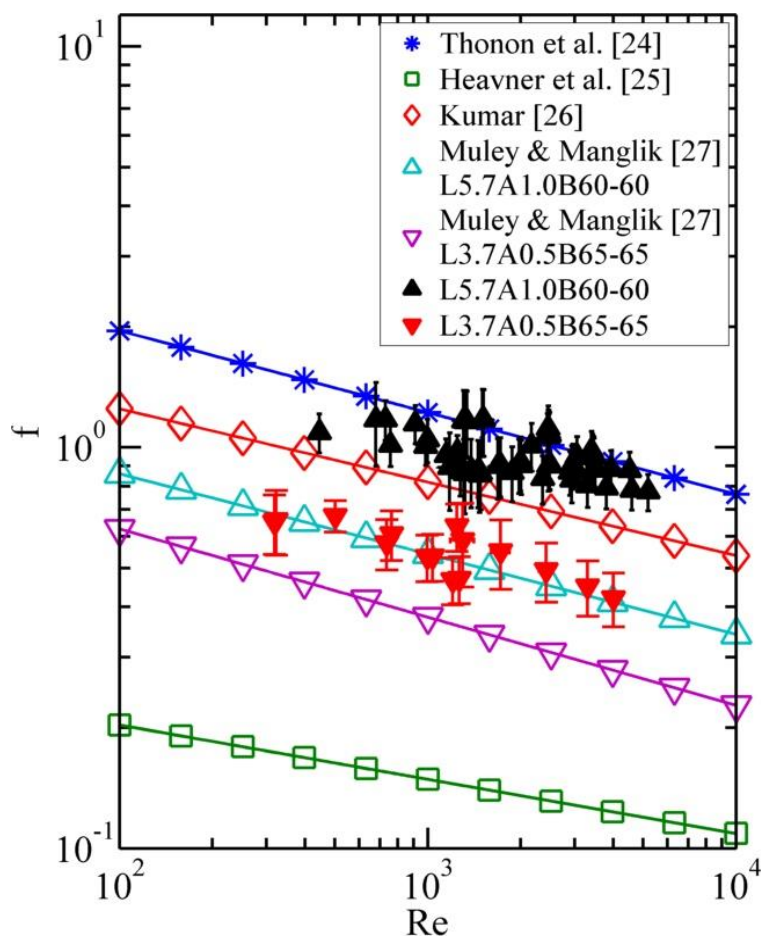

(a)

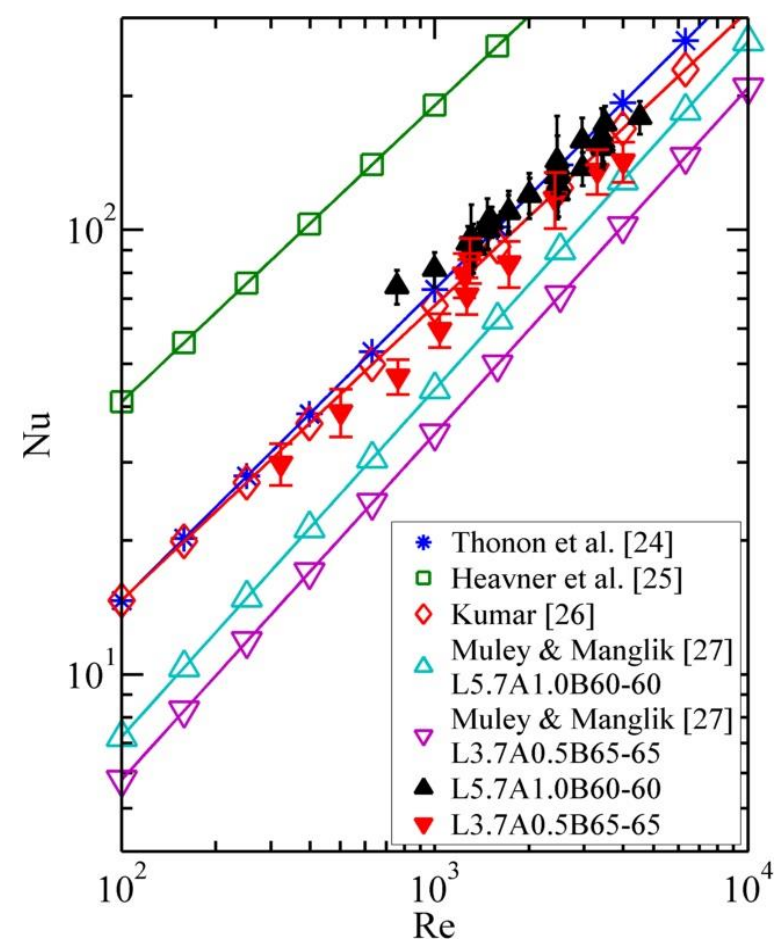

(b)

Fig. 5. Single-phase pressure drop and heat transfer results compared to the prediction methods from literature: Thonon et al. [24],Heavner et al. [25] Kumar [26], Muley and Manglik [27]. (a) mean Fanning friction factor versus Reynolds number, (b) mean Nusselt number versus Reynolds number.

The friction factor and Nusselt number for L5.7A1.0B60-60 are approximately twice as high as those for L3.7A0.5B65-65. The larger friction factor of L5.7A1.0B60-60, which has twice the pressing depth of L3.7A0.5B65-65, can likely be explained by the flow visualizations described by Focke and Knibbe [28]. They found that flow separation could occur for Reynolds numbers as low as 20 and the flow became turbulent above $R e \sim 160$ depending on the chevron angle. Smaller pressing depths might result in smaller separation regions and lower pressure losses. The corrugation aspect ratio $\gamma$ is a good indicator of the trends since the pressure drop increases with $\gamma$. The effect of the small change in chevron angle $\beta$ of $5^{\circ}$ (from $60^{\circ}$ to $65^{\circ}$ ) has less influence on the hydraulic performance.

With the exception of Muley and Manglik [27], the correlations listed in Fig. 5 depended on Reynolds numbers and the chevron angle, and did not include any dependence on the corrugation aspect ratio or surface enlargement factor. For the two geometries tested, these correlations resulted in nearly identical curves since dependence on corrugation angle was negligible. Muley and Manglik [27] included the dependence on the surface enlargement factor $\varphi$. Their correlation 
suggested that L5.7A1.0B60-60 (with $\varphi=1.25$ ) would have a higher friction factor than L3.7A0.5B65-65 (with $\varphi=1.17$ ), which is qualitatively consistent with the observed trends.

The current results show that the existing correlations cannot be used to evaluate the Fanning friction factor with any degree of certainty, and should be an area of future research. The HTC and the frictional pressure drop increase with corrugation aspect ratio, surface enlargement factor, and chevron angle. The Fanning friction factor and Nusselt number followed the correct trends when plotted against the Reynolds number, indicating proper validation of the experimental setup.

\subsection{Average two-phase pressure drop results and comparison of prediction methods to data}

The two-phase frictional pressure gradient versus quality for both geometries are shown in Fig. 6.

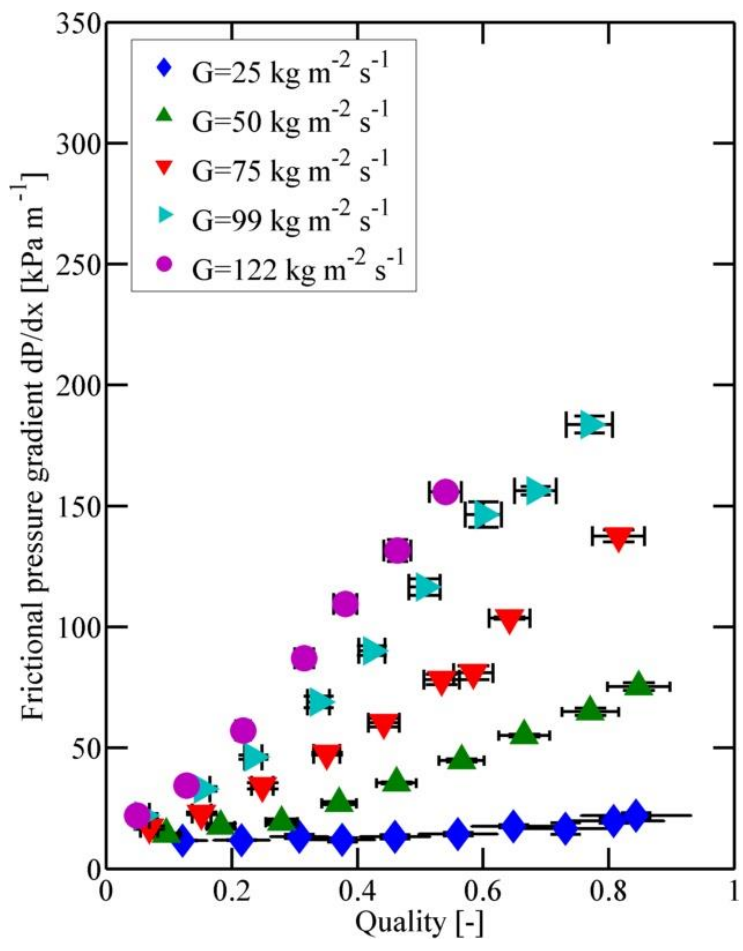

(a)

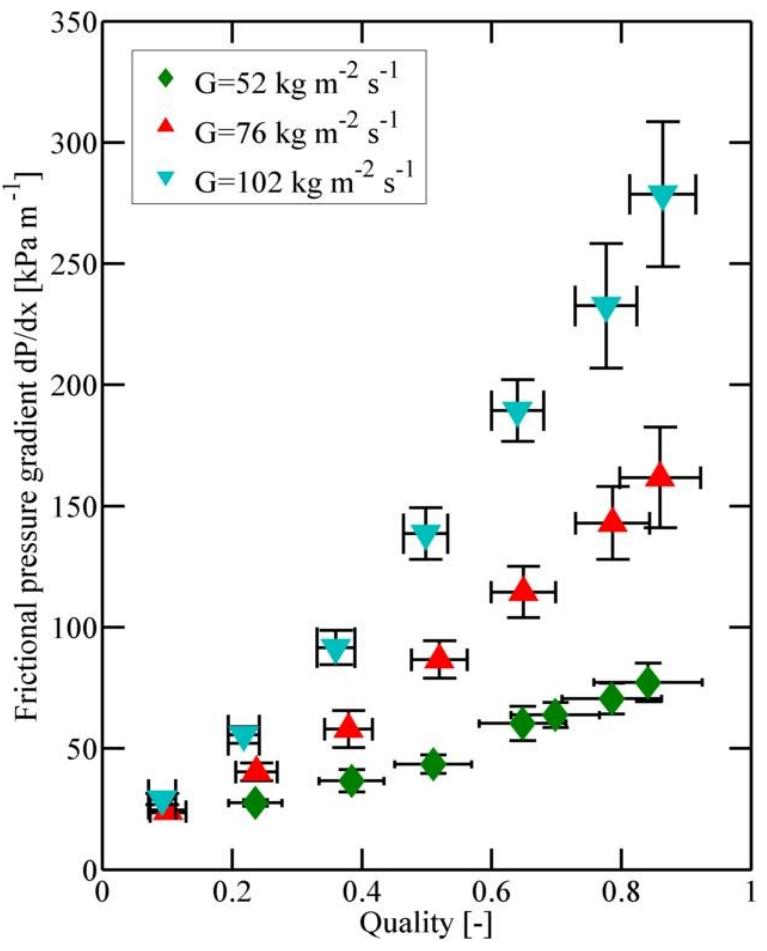

(b)

Fig. 6. Adiabatic two-phase pressure drop results: (a) mean frictional pressure gradient versus mean quality for L5.7A1.0B60-60 geometry, (b) mean frictional pressure gradient versus mean quality for L3.7A0.5B65-65 geometry. 
The frictional pressure gradient increased with quality and mass flux as expected due to the shear stress at the liquid-vapor interface which is the dominant factor in the overall pressure drop. No sudden jumps due to changes in flow pattern were observed.

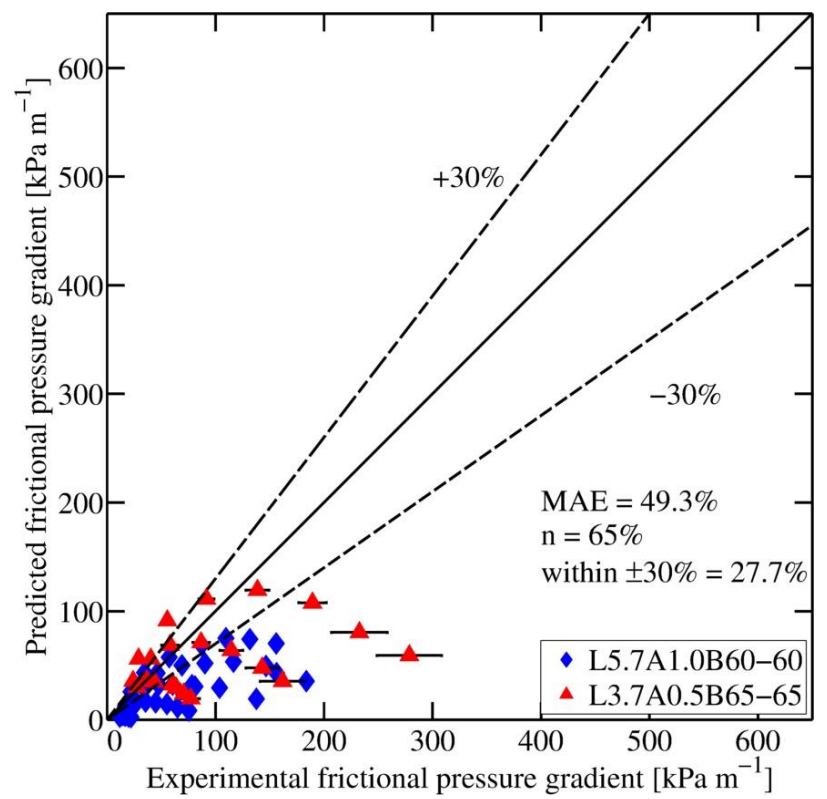

(a)

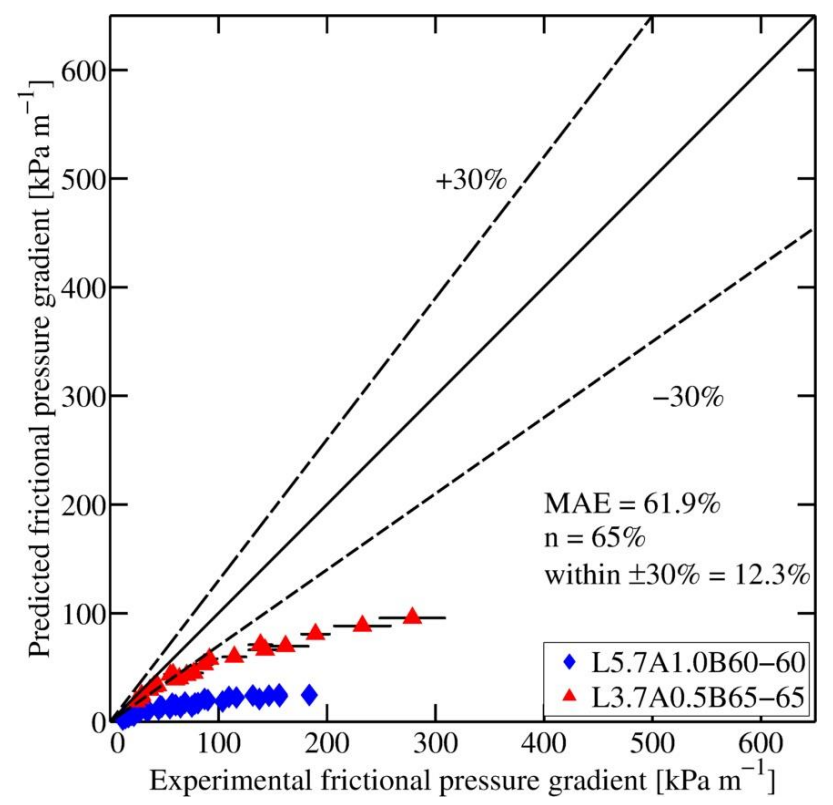

(c)

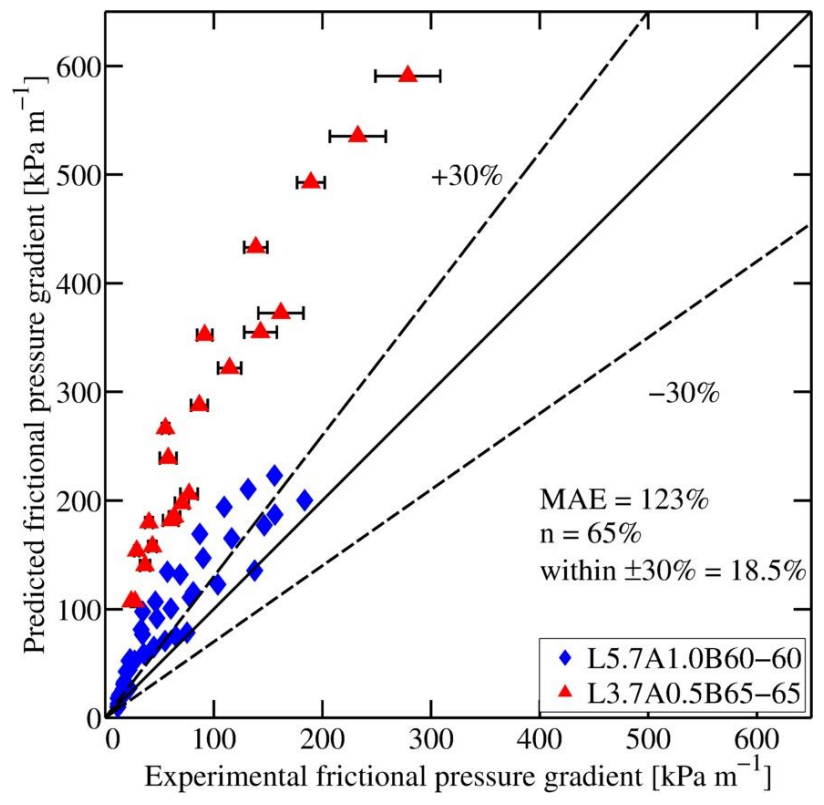

(b)

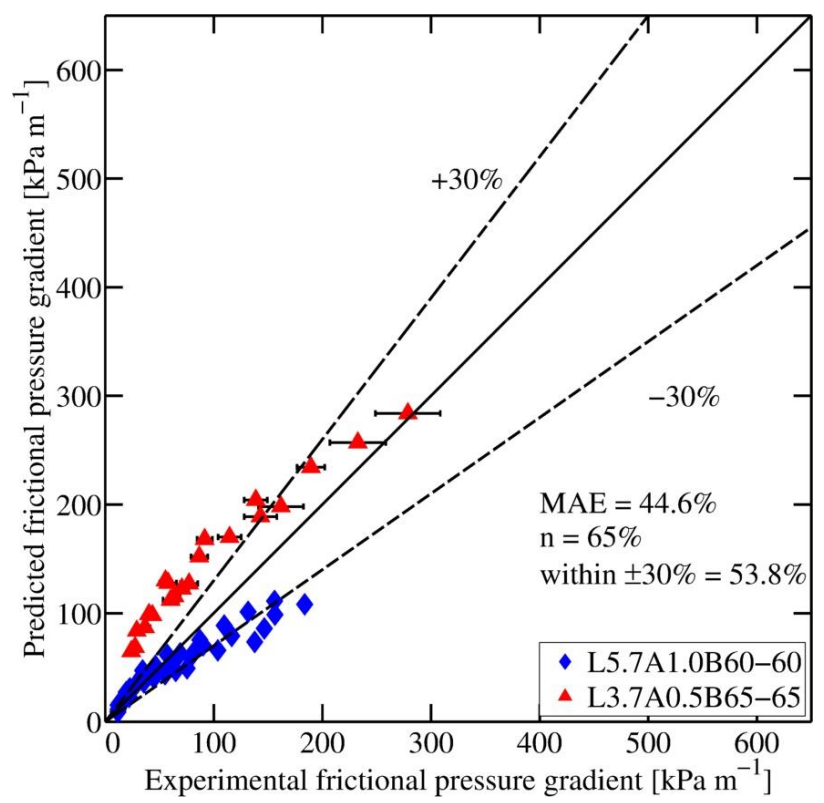

(d)

Fig. 7. Two-phase frictional pressure drop data compared to the most quoted prediction methods from the literature: (a) Nilpueng and Wongwises [21], (b) Khan et al. [29-31], (c) Lee et al. [32], (d) Amalfi et al. $[13,14]$. 
The two-phase pressure gradient data were compared against many of the available correlations. The experimental versus predicted frictional pressure gradient for the best four correlations are shown in Fig. 7 and the correlations along with the experimental test conditions are listed in Table 1.

\begin{tabular}{|c|c|c|}
\hline Authors & Equations & Experimental Test Conditions \\
\hline $\begin{array}{l}\text { Nilpueng } \\
\text { and } \\
\text { Wongwises } \\
{[21]}\end{array}$ & $\begin{aligned} \phi_{l}^{2} & =\frac{(d p / d z)_{t p}}{(d p / d z)_{l}}=\left(1.339+\frac{C}{\mathrm{X}}\right) \quad C=4.492 \\
f_{l} & =4.929 \mathrm{Re}_{l}^{-0.22}\end{aligned}$ & $\begin{array}{l}\mathrm{G}=129-264 \mathrm{kgm}^{-2} \mathrm{~s}^{-1}, \mathrm{~T}_{\mathrm{sat}}=20^{\circ} \mathrm{C} \\
\mathrm{x}=0-0.04, \mathrm{q}=0 \mathrm{kWm}^{-2} \\
\mathrm{~L}-\mathrm{A} 1.25 \mathrm{~B} 55-10 \\
\text { Air-water mixture }\end{array}$ \\
\hline $\begin{array}{l}\text { Khan et al. } \\
\text { [29-31], }\end{array}$ & $\begin{array}{ll}f_{t p}=673336 \operatorname{Re}_{e q}^{-1.3} p_{r}^{0.9} & \beta=30^{\circ} \\
f_{t p}=305590 \operatorname{Re}_{e q}^{-1.26} p_{r}^{0.9} & \beta=45^{\circ} \\
f_{t p}=212 \operatorname{Re}_{e q}^{-0.51} p_{r}^{0.53} & \beta=60^{\circ}\end{array}$ & $\begin{array}{l}\mathrm{G}=5.5-27 \mathrm{kgm}^{-2} \mathrm{~s}^{-1}, \mathrm{~T}_{\mathrm{sat}}=-25^{\circ} \mathrm{C} \text { to }- \\
2{ }^{\circ} \mathrm{C} \\
\mathrm{x}=0.10-0.90, \mathrm{q}=6-49 \mathrm{kWm}^{-2} \\
\mathrm{~L} 6.3 \mathrm{~A} 1.1 \mathrm{~B} 30-30, \mathrm{~L} 6.3 \mathrm{~A} 1.1 \mathrm{~B} 30-60 \\
\mathrm{~L} 6.3 \mathrm{~A} 1.1 \mathrm{~B} 60-60 \\
\text { Ammonia }\end{array}$ \\
\hline $\begin{array}{l}\text { Lee et al. } \\
{[32]}\end{array}$ & $f_{t p}=49.13 \mathrm{Re}_{e q}^{-0.4386} \operatorname{Re}_{l o}^{-0.4074}$ & $\begin{array}{l}\mathrm{G}=14.5-34 \mathrm{kgm}^{-2} \mathrm{~s}^{-1}, \mathrm{~T}_{\mathrm{sat}}=105^{\circ} \mathrm{C} \\
\mathrm{x}=0.10-0.90, \mathrm{q}=15-30 \mathrm{kWm}^{-2} \\
\text { L10A1.25B60-60 } \\
\text { Water }\end{array}$ \\
\hline $\begin{array}{l}\text { Amalfi et al. } \\
{[13,14]}\end{array}$ & $f_{t p}=\left(2.125 \beta^{* 9.993}+0.955\right) \cdot 15.698 W e^{-0.475} B d^{0.255} \rho^{*-0.571}$ & $\begin{array}{l}\text { General prediction method on } 1513 \text { data } \\
\text { points collected from } 13 \text { research } \\
\text { studies between } 1981 \text { and } 2015 \text {. }\end{array}$ \\
\hline
\end{tabular}

Table 1. Summary of the prediction methods for two-phase pressure drops including experimental test conditions

The reader is referred to Amalfi et al. [13,14] for information regarding the operating test conditions and plate geometries for which these models were developed. The Mean Absolute Error is defined as:

$$
M A E=\frac{100}{n} \sum_{j=1}^{n} \frac{\Upsilon_{j, p r e}-\Upsilon_{j, \exp }}{\Upsilon_{j, \exp }}
$$

Nilpueng and Wongwises [21] (Fig. 7a) underestimated the present databank and this correlation was unable to follow the correct trend of the two-phase pressure drop data, especially in the higher qualities region. Khan et al. [33] (Fig. 7b) overestimated the present database because of 
the different test conditions (and ammonia as working fluid) and an incorrect evaluation of the inlet and outlet pressure drops. Lee et al. [32] (Fig. 7c) strongly underestimated the experimental databank since the authors investigated the dryout mechanisms at low mass fluxes using water which has a different behavior compared to the tested refrigerant. This model was able to capture the experimental data only at low refrigerant mass flux. The Amalfi et al. [13,14] correlation (Fig. 7d) provided the best agreement because it was developed over a wide range of operating conditions, fluids and plate geometries. This model slightly overestimated the experimental data due to the inlet and outlet pressure drops as well as extrapolation of the method to higher values of the refrigerant mass flux.

\subsection{Average two-phase heat transfer results and comparison of prediction methods to data}

The area-averaged HTC was calculated by averaging the local HTC over the area shown in Fig. 8a to avoid the entry length, inlet/outlet effects and side effects. The saturation temperatures measured by the five thermocouples are shown in Fig. 8b. The temperature drop in the streamwise direction was consistent according to the measured total pressure drop as well as the variation of the thermodynamic properties along the PHE length. The cross-stream averaged wall temperatures are also plotted in Fig. 8b beside with an example of the local temperature distribution along the black vertical line. The averaged wall-to-temperature difference was fairly constant and inlet/outlet effects were limited to $\sim 10 \mathrm{~mm}$ near the test section inlet and exit. The wall-to-fluid temperature difference (and thus the HTC) did not vary significantly in the streamwise direction for most conditions tested, allowing the HTC averaged over the area within the white box to be correlated against the average quality. 


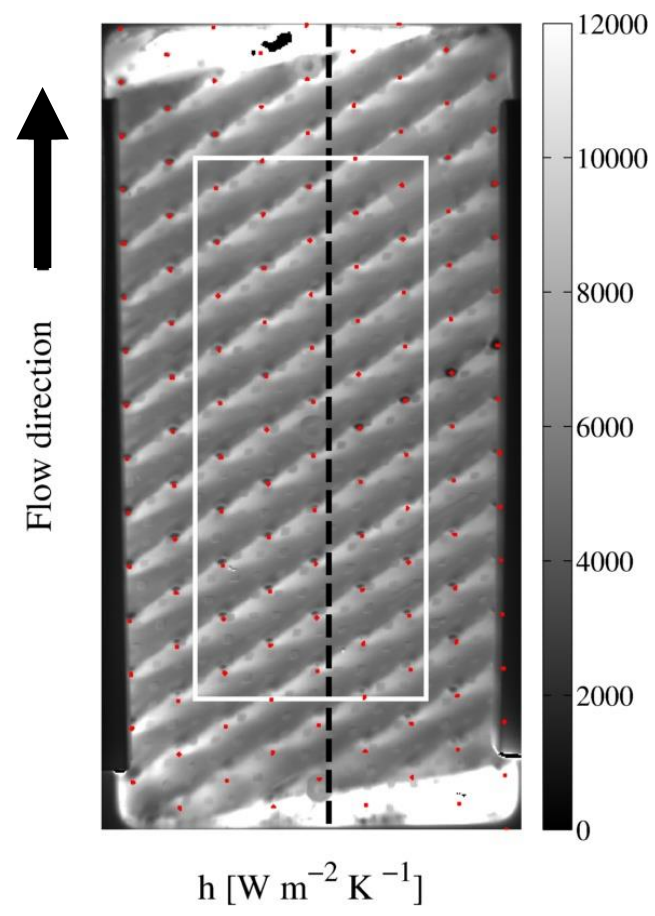

(a)

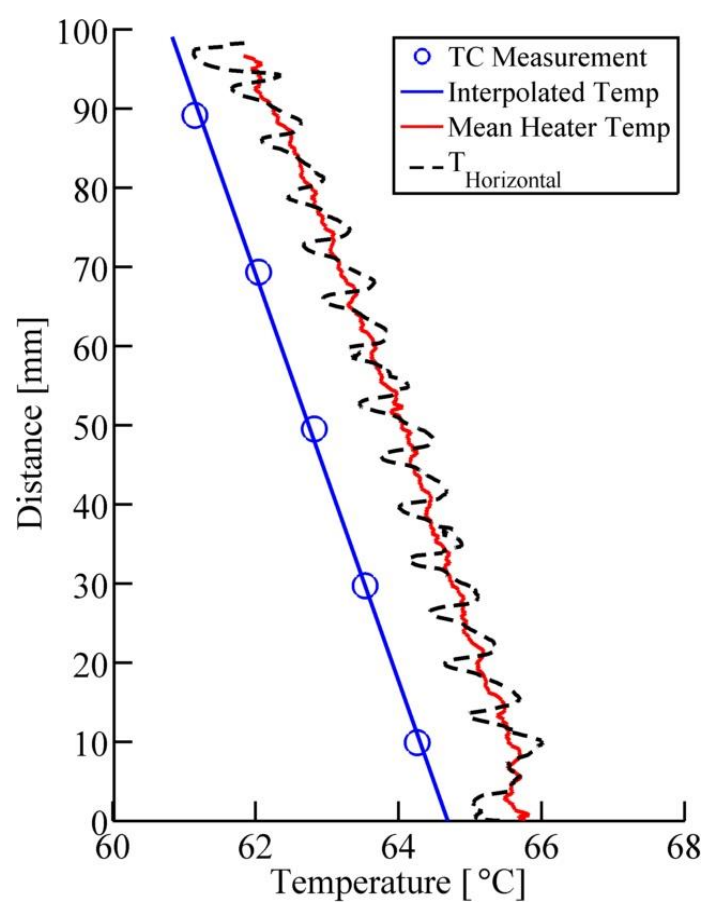

(b)

Fig. 8. Two-phase heat transfer results at $\mathrm{G}=100 \mathrm{~kg} \mathrm{~m}^{-2} \mathrm{~s}^{-1}$ and $\mathrm{x}_{\mathrm{i}}=0.5$ : (a) time averaged HTC distribution for L5.7A1B60-60 with dots indicating the contact points and the white box representing the area that was used for the overall HTC computation, (b) saturation temperature and mean heater temperature averaged over the partial width of the plate against the time averaged temperature along the dotted black line.

The uncertainty in HTC increased with quality since the wall-to-fluid temperature difference decreased. This could be partially mitigated by increasing the heat flux, but the maximum imposed heat flux was limited by the temperatures at the contact points that could become high enough to damage the tape used as an electrical insulator between the two film heaters. At higher inlet quality, the applicable heat flux lead to the partial dryout of the liquid film as shown in Fig. 9. The left image illustrates the temperature from the IR-camera which highlights the presence of dryout in the upper half of the test section. The dryout area grew larger in size along the zig-zag pattern as indicated by the arrows in Fig. 9a as will be discussed later. The heat transfer distribution computed from the temperature data for the same operating conditions is shown in Fig. 9b. The technique to calculate HTC assumed that all the heat generated by the heaters is transferred into the fluid. However, when dryout occurs, the majority of heat generated is conducted into the substrate, and the heat flux into the fluid became essentially zero while the wall-to-fluid temperature difference increased (Fig. 9c). Since a constant heat flux was assumed, 
the calculated HTC was higher compared to the actual heat transfer. In order to compute the true local HTC when dryout occurs, the transient heat conduction into the substrate as well as the temperature gradient at the wall-fluid interface needs to be calculated as described in Kim et al. [34]. This procedure is beyond the scope of this paper, however. The HTC data recorded during the dryout regime has been marked in the figures below and should be considered to be unreliable.

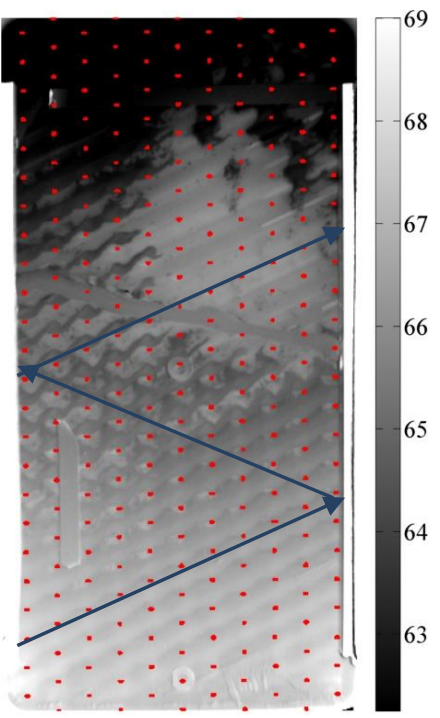

Heater Temperature $\left[{ }^{\circ} \mathrm{C}\right]$

(a)

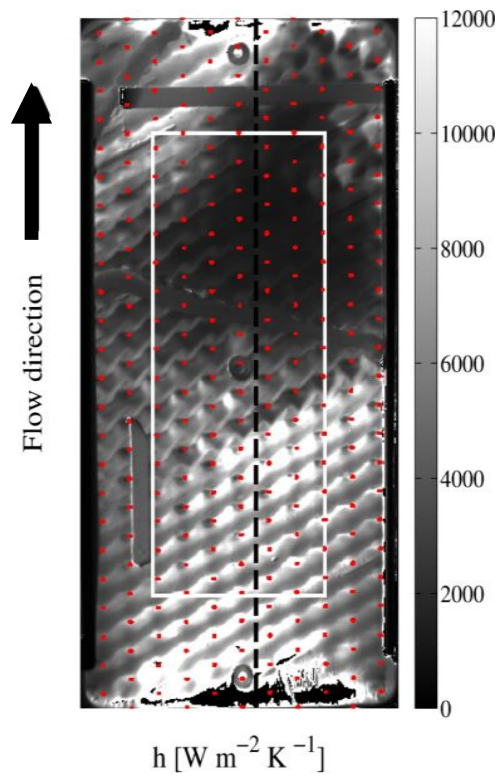

(b)

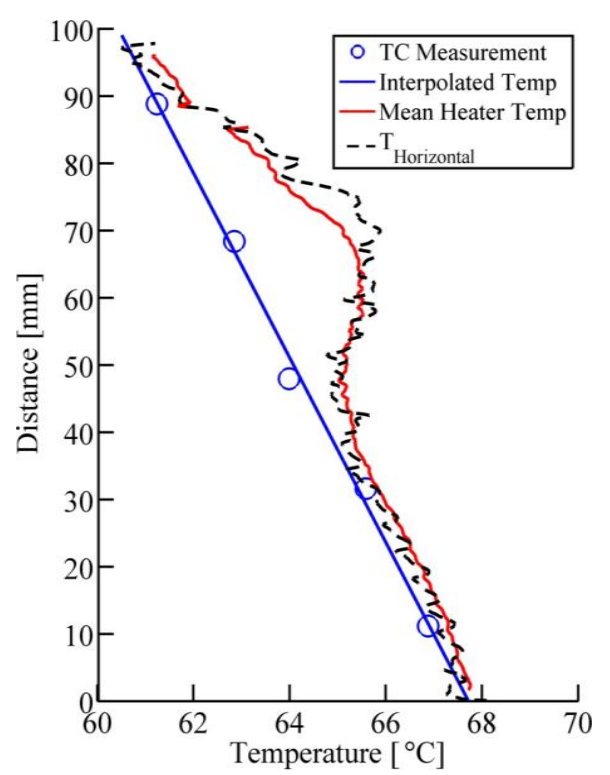

(c)

Fig. 9. Partial dryout for L3.7A0.5B65-65 at $\mathrm{G}=100 \mathrm{~kg} \mathrm{~m}-{ }^{2} \mathrm{~s}^{-1}$ and $\mathrm{x}_{\mathrm{i}}=0.8$ : (a) instantaneous temperature distribution, with dots indicating the contact points and arrows show the direction of increasing dryout area, (b) time average HTC, with the white box indicating the area that was used for the overall HTC, (c) saturation temperature and mean heater temperature averaged over the partial width of the plate versus the time averaged temperature along the dotted black line.

Fig. 10 shows the two-phase HTC for both geometries plotted against the mean quality. As expected, HTC increased with quality and mass flux for both geometries for the data where dryout does not occur. At low qualities the mass flux had a small effect on HTC, while at higher qualities, the effect of the mass flux became more significant. Similar results were observed by Djordjevic and Kabelac [8] who investigated flow boiling of refrigerants at high mass fluxes as in this study. 


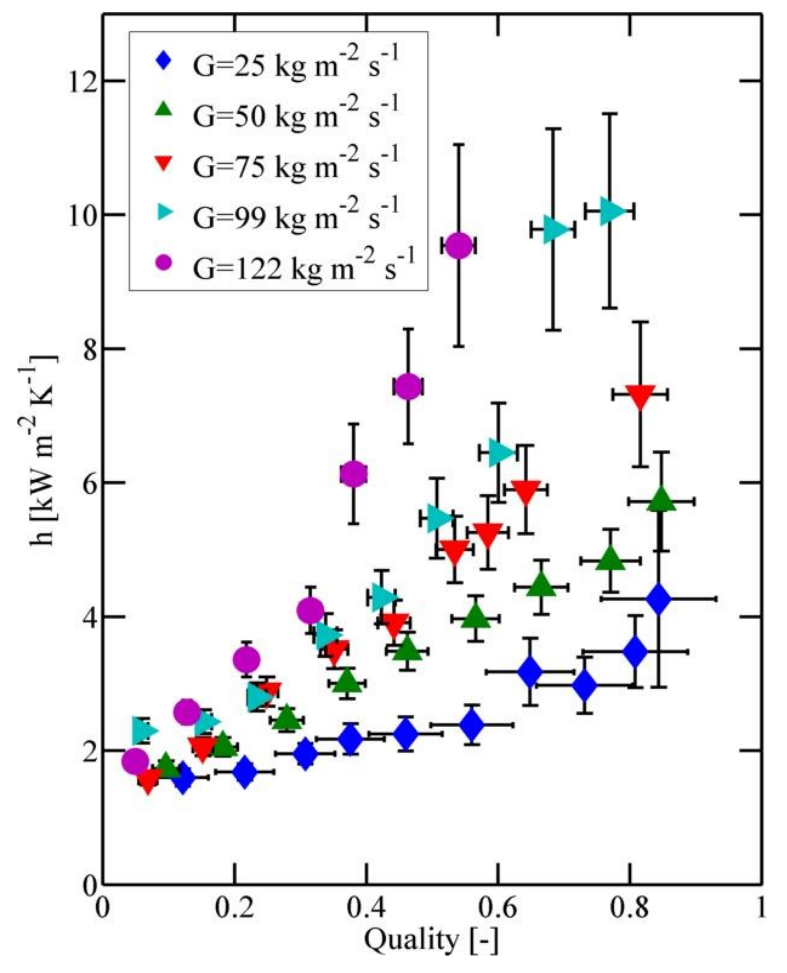

(a)

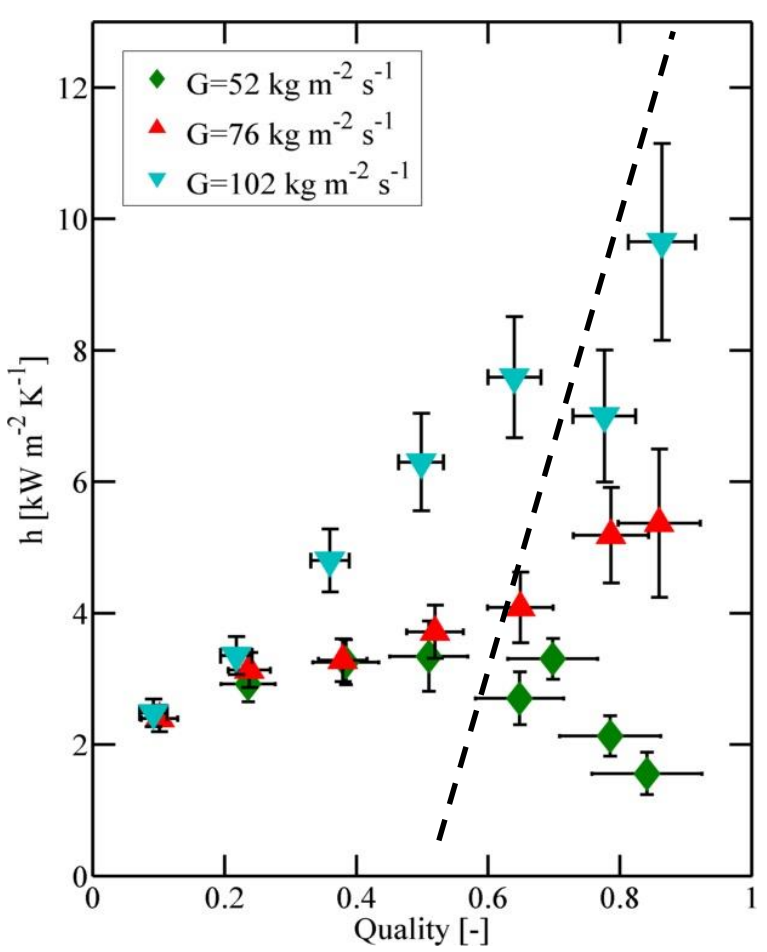

(b)

Fig. 10. Average two-phase heat transfer results: (a) HTC versus quality for L5.7A1.0B60-60, (b) HTC versus quality for L3.7A0.5B65-65. Dryout occurred for the data to the right of the dotted line and are therefore unreliable.

The current two-phase heat transfer data were compared to models available in the literature. The results are presented in Fig. 11 and the correlations along with the experimental test conditions are listed in Table 2. The models of Donowski and Kandlikar [35] (Fig. 11a) and Hsieh and Lin [36] (Fig. 11c) agreed well with the data. Han et al. [37] (Fig. 11b) was able to predict the experimental data at low mass flux conditions since the authors included in their model the effect of the hydraulic diameter, wavelength of the surface corrugation, and chevron angle. The agreement is much worse at higher mass fluxes. The Amalfi et al. [13,14] method (Fig. 11d), even though developed with a consolidated experimental databank, was able to capture the heat transfer data at low mass fluxes, but overall underestimated the present data. The poor agreement could be due to the present approach of evaluation of the inlet and outlet pressure drops, which play an important role in the local HTC calculation. 


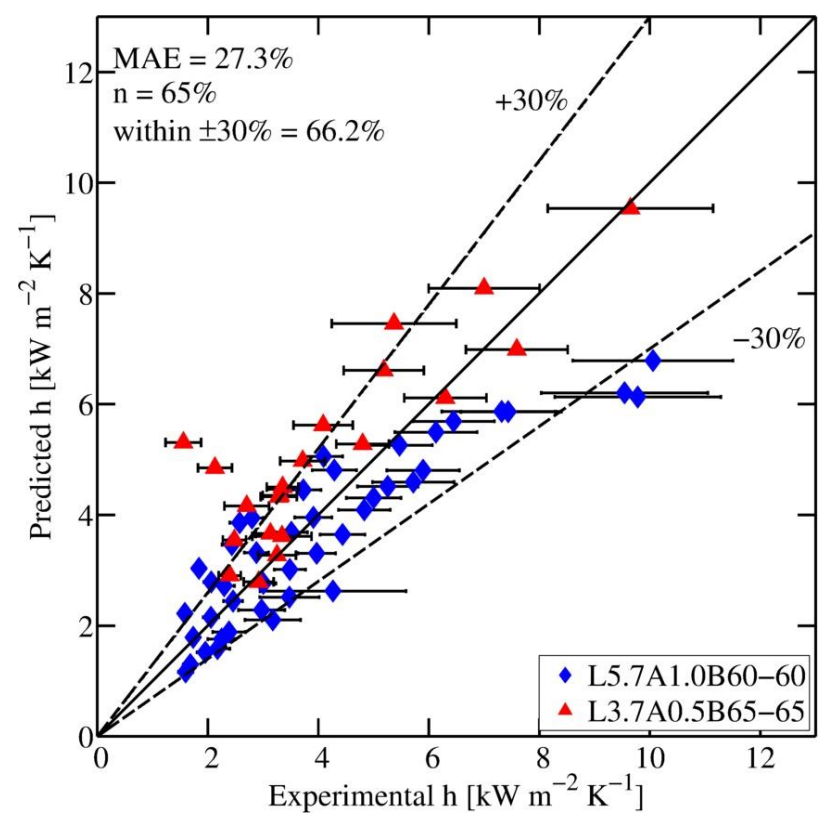

(a)

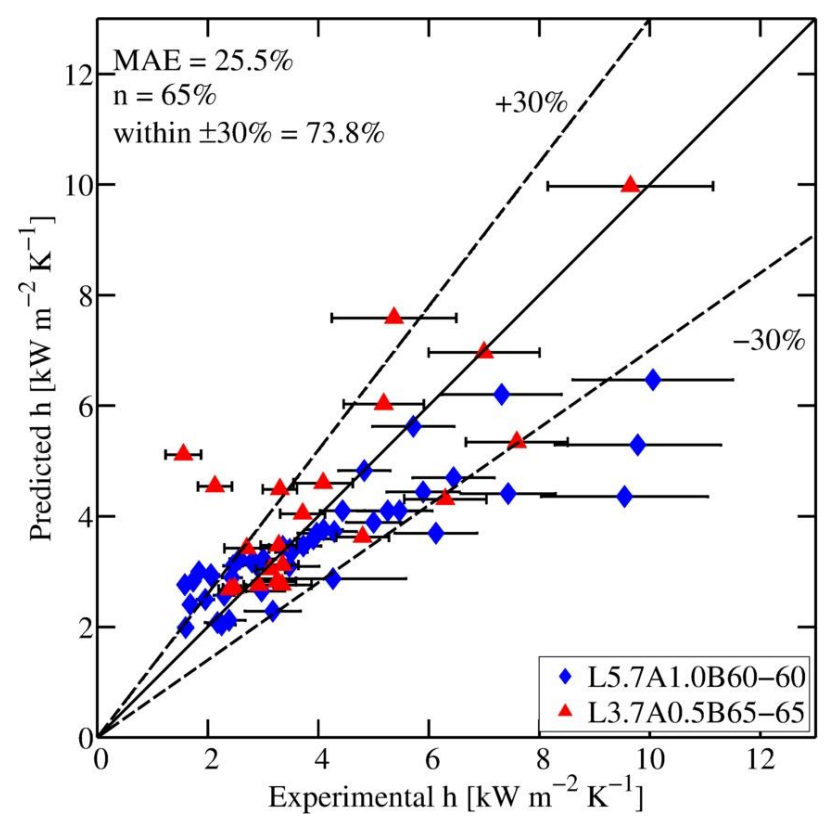

(c)

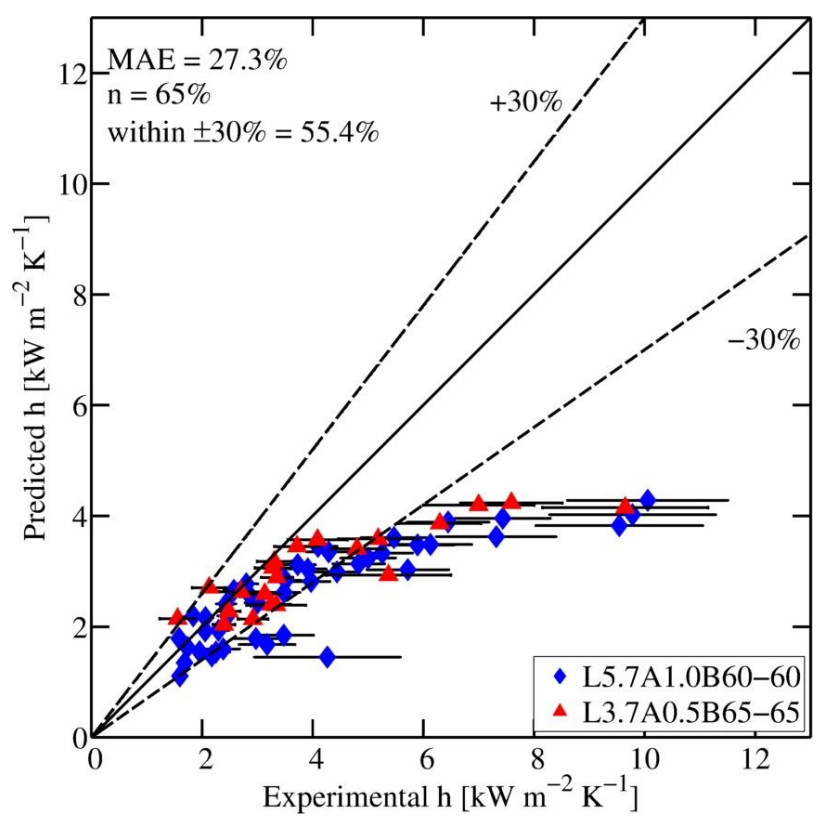

(b)

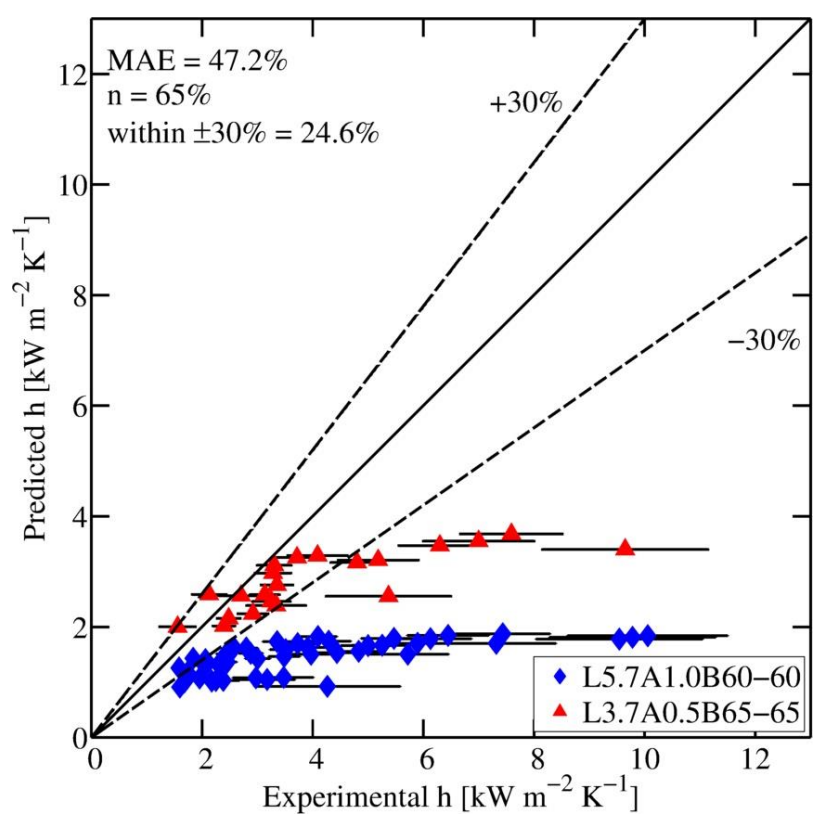

(d)

Fig. 11. Two-phase heat transfer data compared to the most quoted prediction methods from the literature: (a) Donowski and Kandlikar [35], (b) Han et al. [37], (c) Hsieh and Lin [36], (d) Amalfi et al. [13,14]. 


\begin{tabular}{lll}
\hline Authors & Equations & Experimental Test Conditions \\
\hline Donowski & $S=\frac{N u_{t p}}{N u_{l o}}=\left[1.184 C^{-0.3}+225.5 B o^{2.8}\right](1-x)^{0.003}$ & $\mathrm{G}=55-70 \mathrm{kgm}^{-2} \mathrm{~s}^{-1}, \mathrm{~T}_{\text {sat }}=25.5-$ \\
Kandlikar & $N u_{l o}=0.2875 \mathrm{Re}_{l o}^{0.78} \mathrm{Pr}_{l}^{1 / 3}$ & $31{ }^{\circ} \mathrm{C}$ \\
{$[35]$} & & $\mathrm{x}=0-0.90, \mathrm{q}=11-15 \mathrm{kWm}^{-2}$ \\
& & $\mathrm{~L} 10 \mathrm{~A} 1.65 \mathrm{~B} 60-60$ \\
& $\mathrm{R} 134 \mathrm{a}$
\end{tabular}

Table 2. Summary of the prediction methods for two-phase heat transfer including experimental test conditions

The trend of the mean HTC against the associated frictional pressure gradient for both plate geometries is shown in Fig. 12. For the no dryout cases, the trend in the data could be well described by a linear relationship. The L5.7A1B60-60 geometry provides slightly higher heat transfer than L3.7A0.5B65-65 for a given pressure gradient, as was seen for the single-phase heat transfer results. 


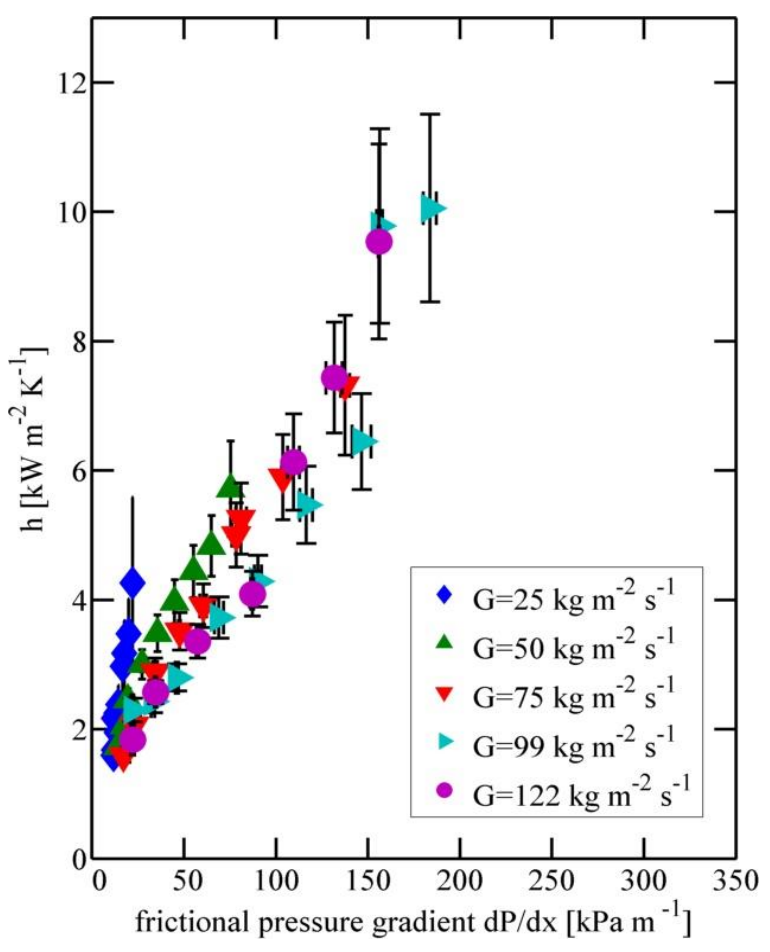

(a)

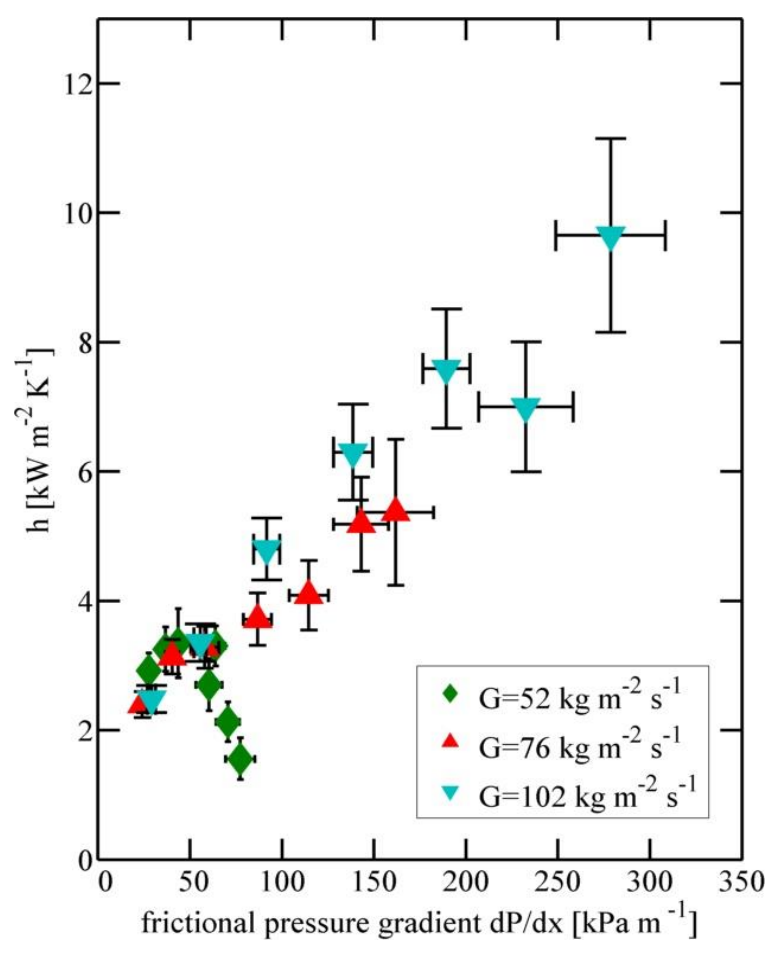

(b)

Fig. 12. Average HTC versus frictional pressure gradient for both PHEs: (a) test section with L5.7A1.0B60-60, (b) test section with L3.7A0.5B65-65.

\subsection{Local two-phase heat transfer results and dryout mechanisms}

In order to analyze the local HTC distribution within the PHE, the data from a $3 \times 3$ set of unit cells was averaged to obtain the heat transfer distribution within a representative cell as shown in Fig. 13 and Fig. 14 for $\mathrm{G}=100 \mathrm{~kg} \mathrm{~m}^{-2} \mathrm{~s}^{-1}$ and various qualities. The center of the cell and the corners are contact points between the plates. The same heat transfer pattern is expected on the opposite plate, but mirrored. In both geometries, the lowest HTC was found to be at the contact point, while the highest HTC was located on the upstream side of a furrow where the fluid accelerates.

The largest heat flux occurred just to the right of the contact point and may be associated with a local vortex. The lowest HTC occurred downstream of the contact point and was likely due to an accumulation of stagnant fluid. As the quality increased, the semi-continuous band of high HTC on the upstream side of the furrow "split" due to the formation and rewetting of a dry patch. For L3.7A0.5B65-65, dry patches were observed more frequently and were larger in size than for L5.7A1.0B60-60. Although the mass fluxes in both PHE geometries were equal, the 
mass flux in the preheater changed due to the constant tube diameter. The mass flux in the preheater for L5.7A1.0B60-60 was twice as high as for L3.7A0.5B65-65, resulting in a more unstable flow, especially at higher inlet qualities. These oscillations were clearly visible in the IR-videos as well as flow visualizations.

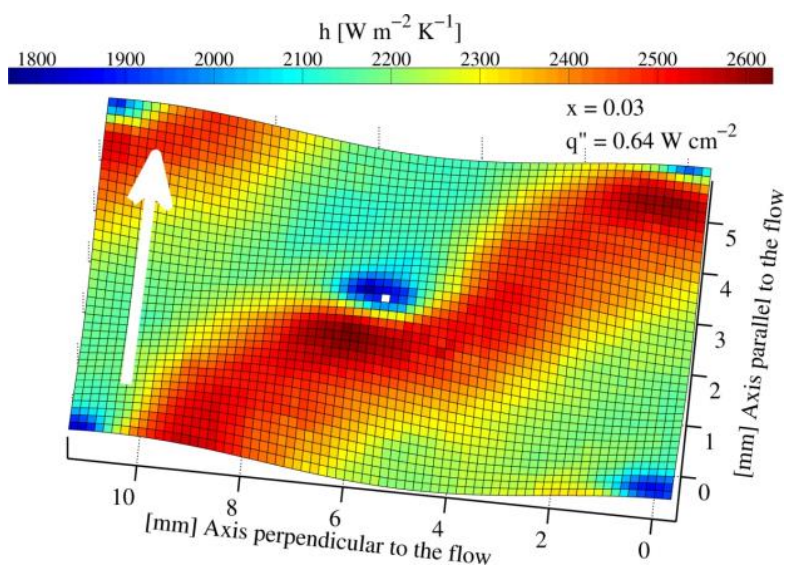

(a)

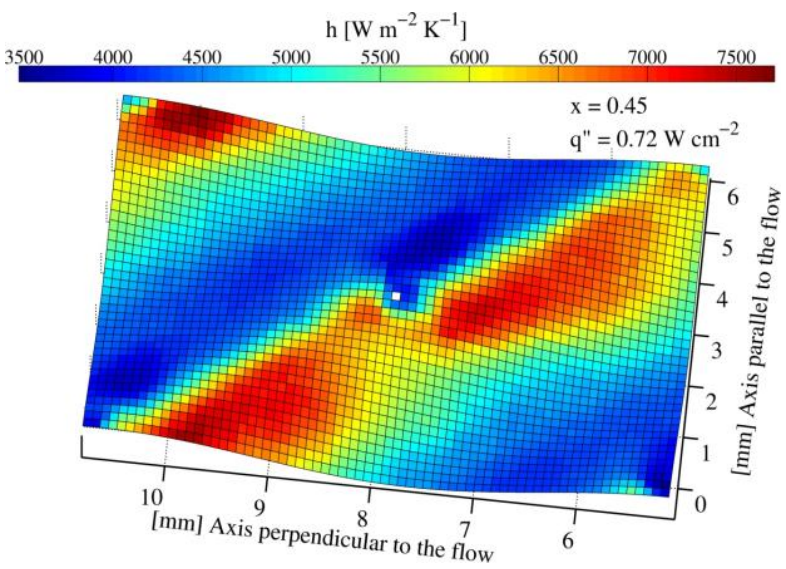

(c)

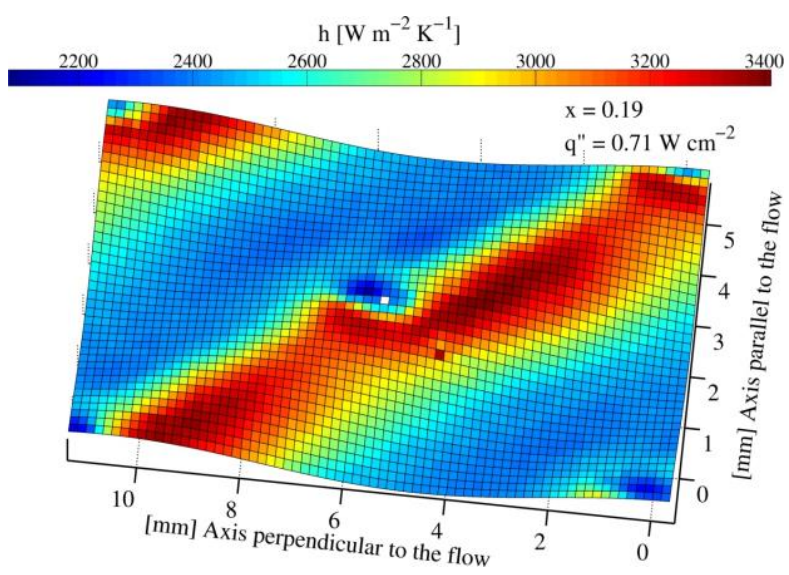

(b)

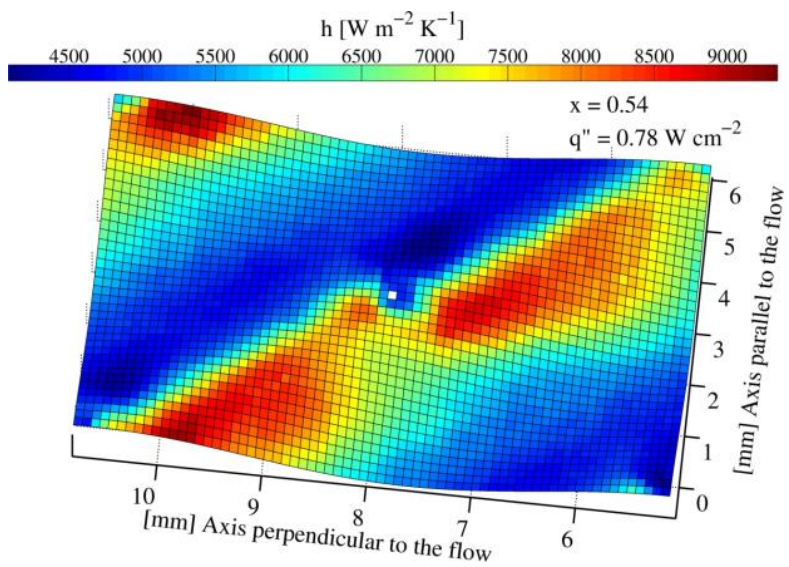

(d)

Fig. 13. Local time averaged HTC distribution in a single cell for L5.7A1.0B60-60 at G $=100 \mathrm{~kg} \mathrm{~m}_{-}{ }^{2} \mathrm{~s}^{-}{ }^{1}$, the white squares shows the location of the contact point and the white arrow in (a) the flow direction, quality and heat flux are listed in the upper right corner. 


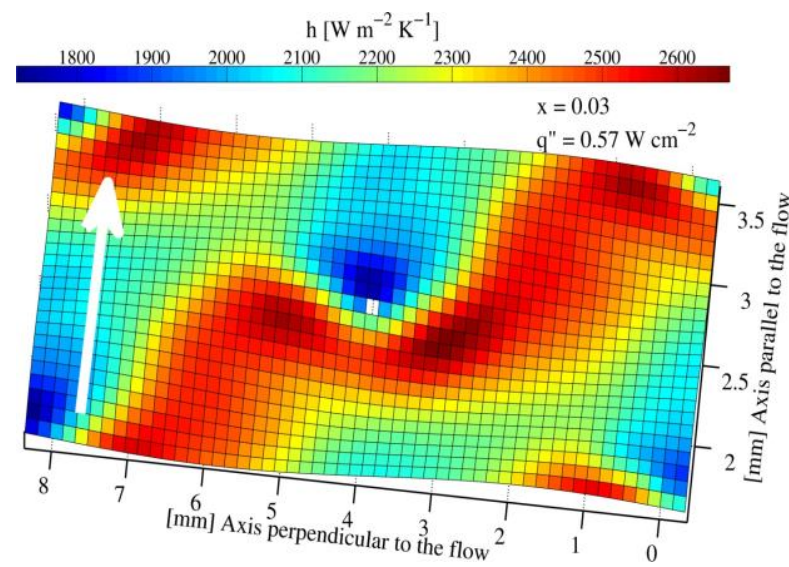

(a)

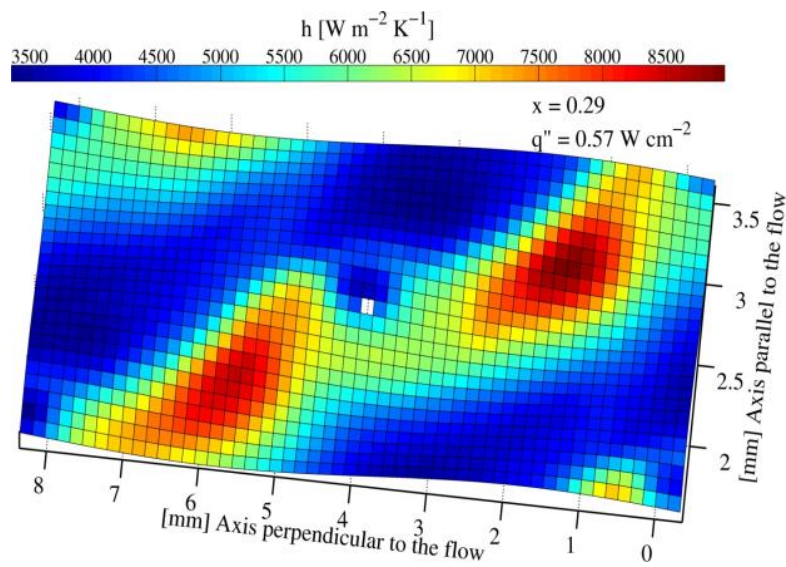

(c)

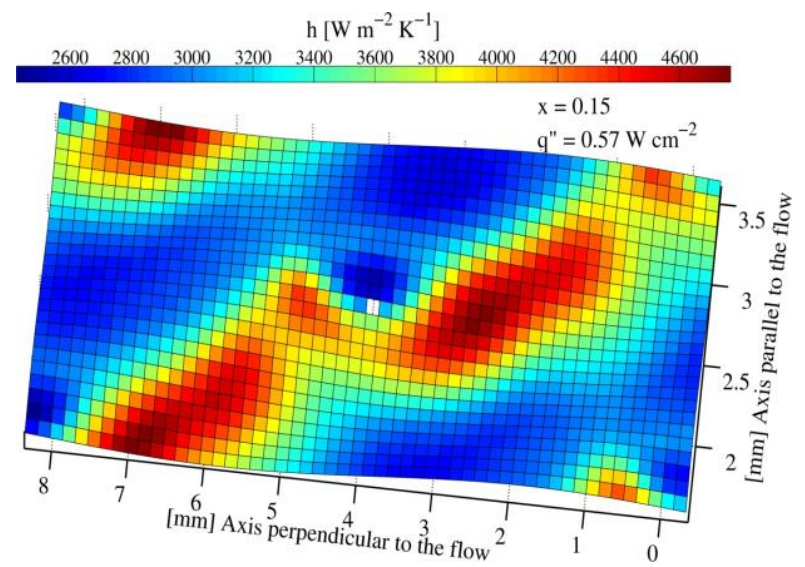

(b)

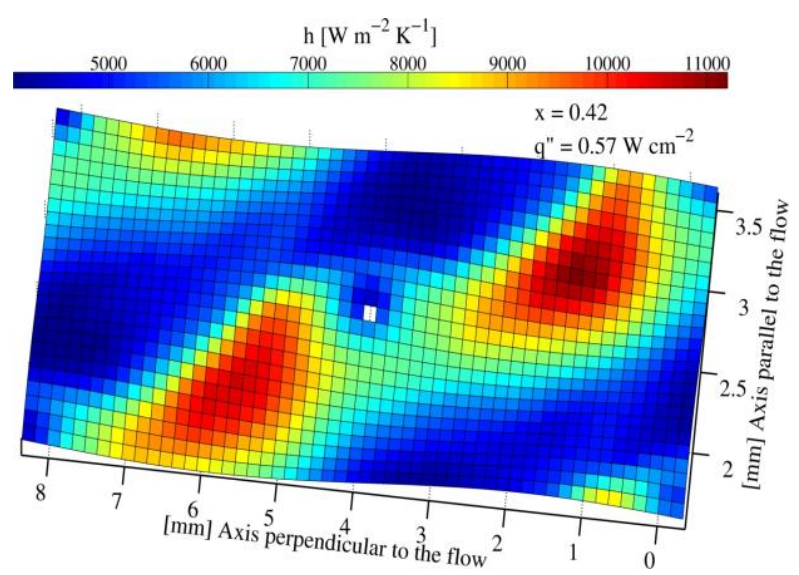

(d)

Fig. 14. Local time averaged HTC distribution in a single cell for L3.7A0.5B65-65 at $\mathrm{G}=100 \mathrm{~kg} \mathrm{m-}{ }^{2} \mathrm{~s}^{1}$, the white squares shows the location of the contact point and the white arrow in (a) the flow direction, quality and heat flux are listed in the upper right corner.

As previously mentioned, partial dryout was observed for the L3.7A0.5B65-65 geometry. Instantaneous temperature measurements of the heated film were used to analyze the location and propagation of the dryout areas in a PHE cell. The local temperature distribution was a good indicator to identify which areas were wet and which were not since the temperature at a dry spot increased rapidly. The temperature distribution in the L3.7A0.5B65-65 cell shown in Fig. 15 illustrates how dryout progresses. At low qualities (Fig. 15a), the temperature distribution indicates HTC is similar to that shown in Fig. 14 since no dryout has yet occurred (high temperatures correspond to low HTC and vice versa). When the inlet quality is increased (Fig. 15b), the point of lowest temperature (highest HTC) just upstream of the contact point 
experiences an increase in temperature indicating local dryout. With further increases in flow quality (Fig. 15c and Fig. 15d), the dry patch gradually enlarges until the side of the furrow upstream of the contact point is covered by vapor and liquid is only left on the downstream side of the furrow.

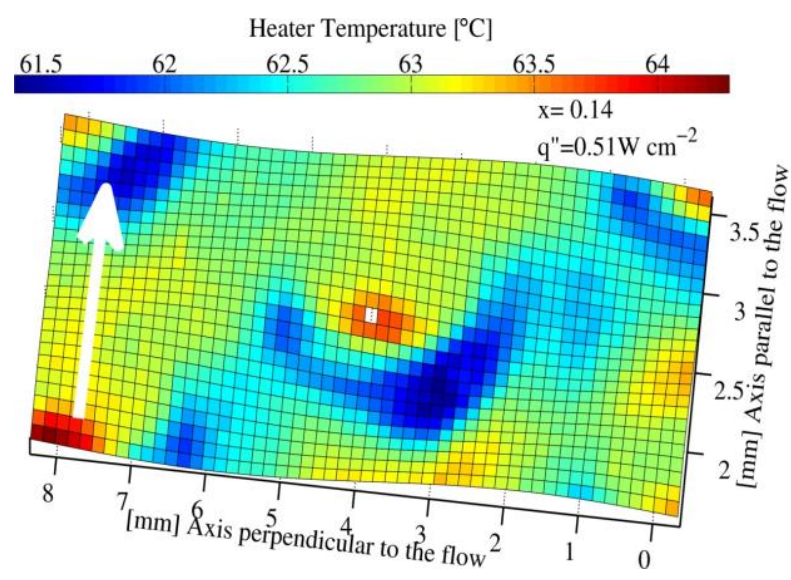

(a)

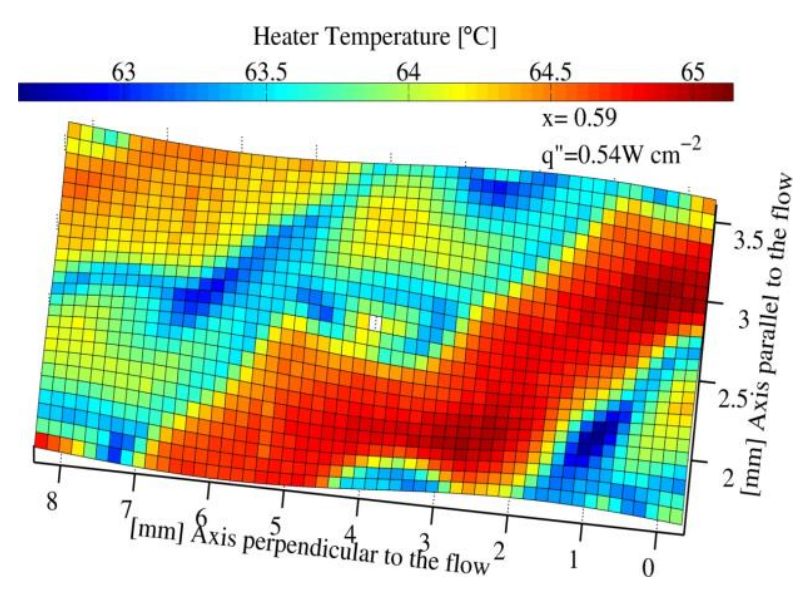

(c)

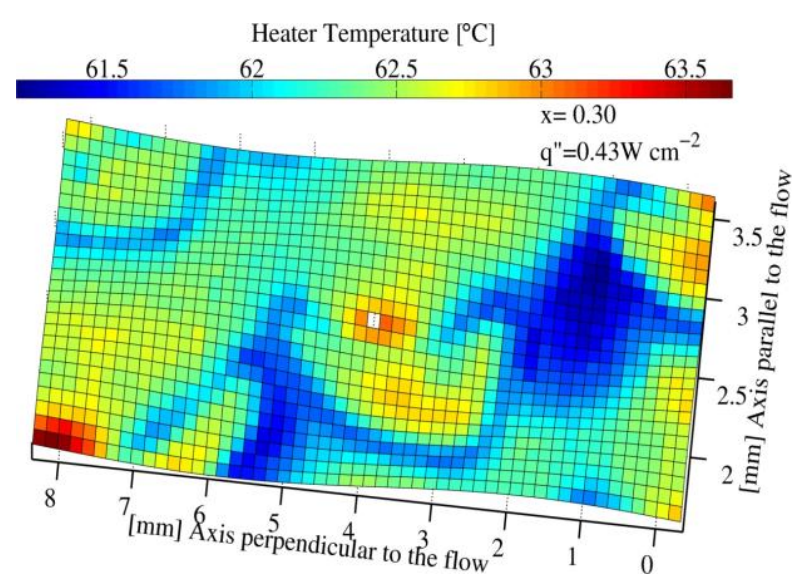

(b)

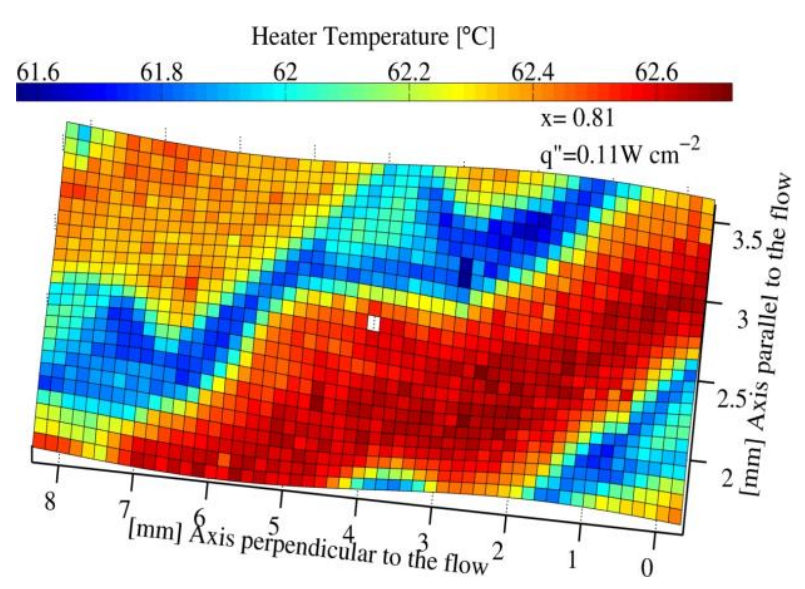

(d)

Fig. 15. Local temperature distribution in a single cell for L3.7A0.5B65-65 at $\mathrm{G}=50 \mathrm{~kg} \mathrm{~m}^{-2} \mathrm{~s}^{-1}$, the white squares shows the location of the contact point and the white arrow in (a) the flow direction, quality and heat flux are listed in the upper right corner.

\subsection{Flow visualization}

The flow pattern in the PHE channel under adiabatic two-phase flow was visualized at various inlet qualities using a high speed video camera at $800 \mathrm{~Hz}$. For these tests, the PHE channel was created by pressing two polycarbonate plates together without the heater. The 
channel was back lit by an array of LEDs. The quality change along the test section due to the two-phase pressure drop was found to be negligible.

The results of the flow visualizations for both geometries are shown in Fig. 16 and Fig. 17.

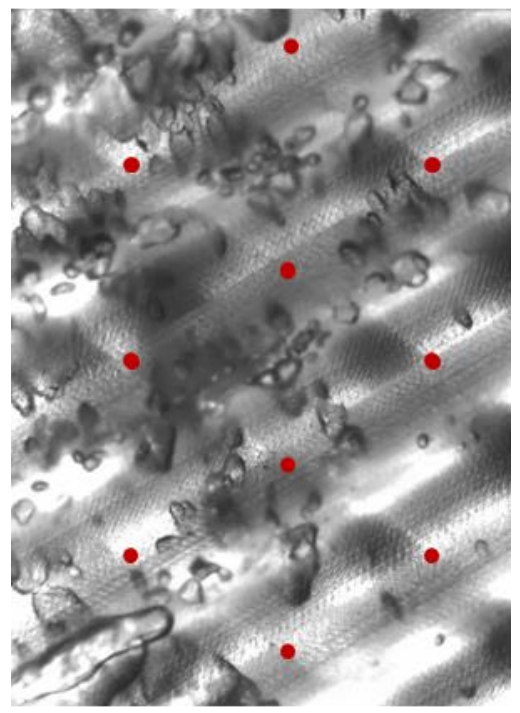

(a)

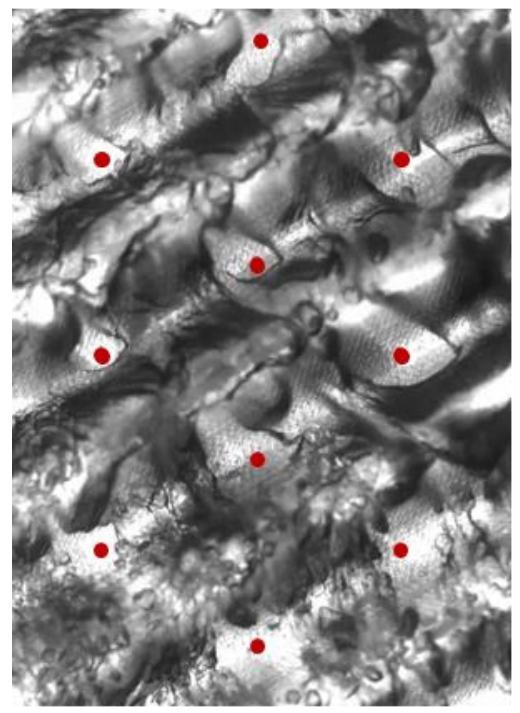

(b)

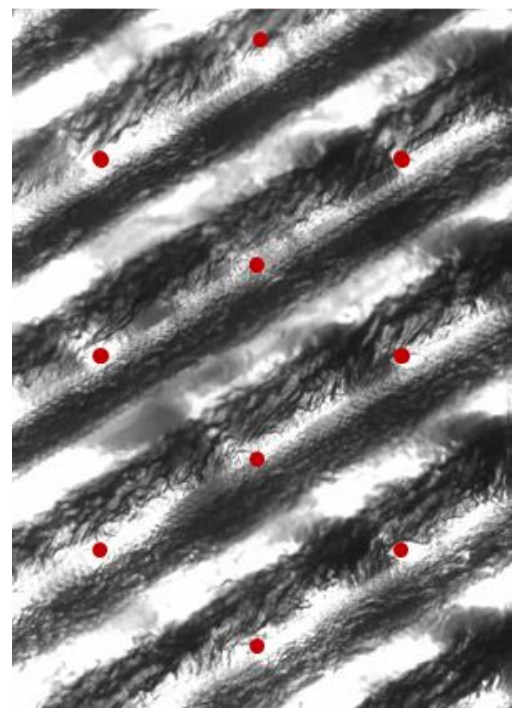

(c)

Fig. 16. Two-phase flow visualization for L5.7A1.0B60-60 at $\mathrm{G}=100 \mathrm{~kg} \mathrm{~m}^{-2} \mathrm{~s}^{1}$ : (a) bubbly flow $\mathrm{x}=$ 0.02 , (b) churn flow $x=0.05$, (c) film flow $x=0.30$. The red circles indicate contact points between the plates.

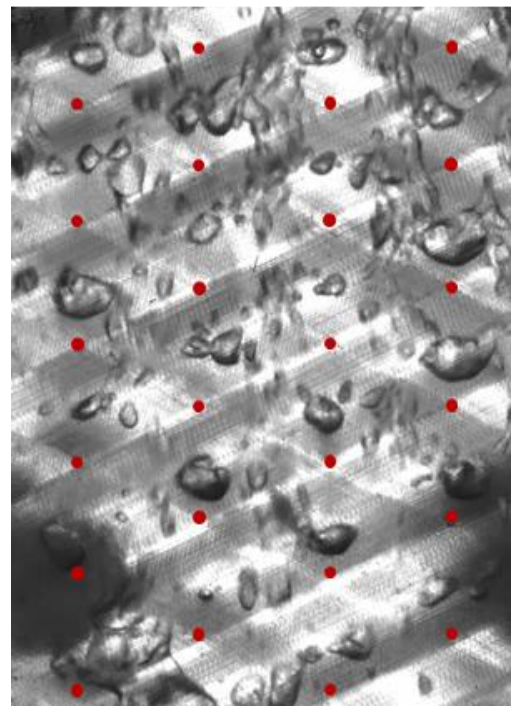

(a)

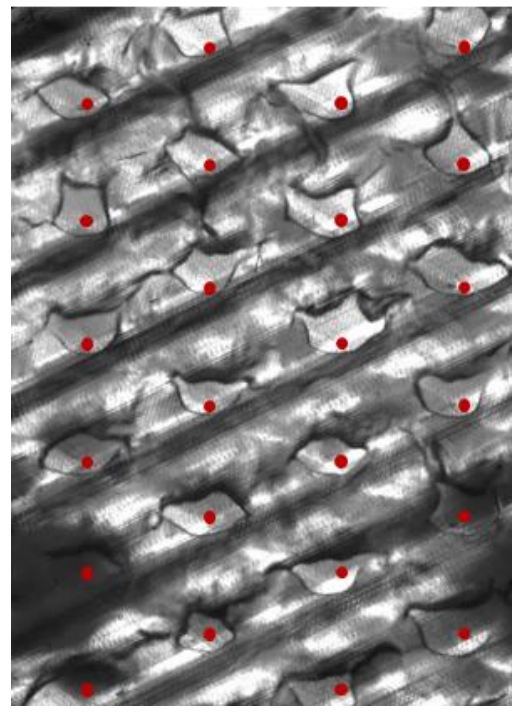

(b)

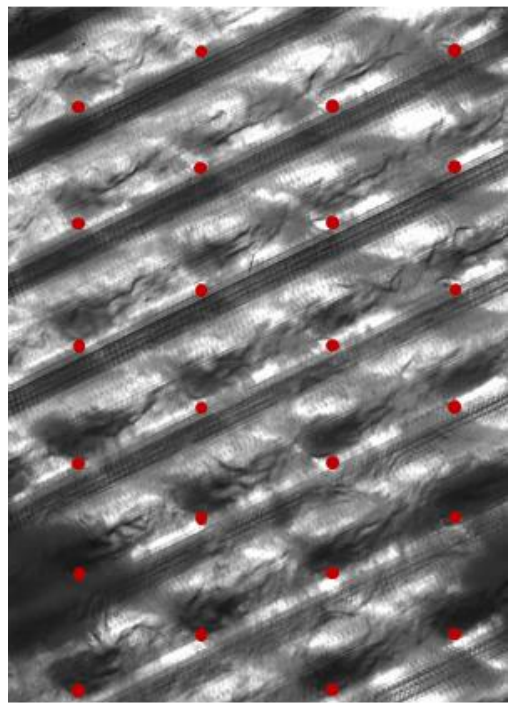

(c)

Fig. 17. Two-phase flow visualization for L3.7A0.5B65-65 at $\mathrm{G}=100 \mathrm{~kg} \mathrm{~m}^{-2} \mathrm{~s}^{1}$ : (a) bubbly flow $\mathrm{x}=$ 0.05 , (b) churn flow $\mathrm{x}=0.15$, (c) film flow $\mathrm{x}=0.4$. The red circles indicate contact points between the plates. 
Three patterns similar to those observed by Tribbe and Mueller-Steinhagen [17] were seen. At low qualities $(\mathrm{x}<0.05)$ the flow was in the bubbly flow regime independent of the mass flux. Individual bubbles could become trapped for a short time where the spacing between both plates was maximum as shown in Fig. 17a and Fig. 18a. Low HTC was measured in these areas. With increasing quality, individual bubbles merged to form a liquid layer that covered the entire plate except at the contact points where dry spots periodically formed. For qualities greater than $x=0.2$, the liquid formed a stable film on the surface until dryout occurred at very high qualities. The size of the vapor region around the contact points decreased as the quality increased.

\section{Conclusions}

Measurements of local flow boiling heat transfer and pressure drop within two PHE geometries were obtained using IR thermography. The PHE channels were created by pressing corrugated plates together, one made from IR-transparent $\mathrm{CaF}_{2}$ and the other from a compliant plastic (polycarbonate). Both plates were heated by electric film heaters epoxied onto the corrugated surfaces. Five equally spaced thermocouples and five pressure taps were used to measure the temperature and pressure distribution. 3D-printed inlet and outlet flow distributors were used to create a flow that became thermally and hydrodynamically fully developed after a short entrance length. The experimental test facility and data reduction techniques were validated by comparing single-phase measurements with correlations from the literature.

The pressure gradient and HTC for both geometries increased steadily with inlet quality at low to intermediate qualities. At high inlet qualities the measurement uncertainty in HTC became unacceptably large since the wall-to-fluid temperature difference was small even at the highest heat input which was restricted by local burnout at the contact points for L5.7A1.0B60-60 and partial dryout for L3.7A0.5B65-65. The HTC varied linearly with the pressure gradient for both geometries for the cases where dryout did not occur. When comparing the two-phase data to existing correlations very little agreement was observed, which is likely due to the fact that most researchers based their findings on global PHE data which include the inlet and outlet port pressure drops. The end ports of a PHE have a significant effect on the overall performance, potentially obscuring the local data if not taken into account. Using different liquids and small variations in geometries could also have a substantial effect on each data set. 
The time averaged, spatially resolved HTC distribution measurements within a representative PHE cell during two-phase flow indicated a minimum at the contact point, an elevated HTC on the upstream side of a furrow, and a maximum located just upstream of the contact point. As the inlet quality increased, the heat transfer distribution became increasingly non-uniform. At high qualities the maximum HTC located upstream of the contact points began to disappear for the L3.7A0.5B65-65 geometry indicating local dryout. Adiabatic two-phase flow visualizations indicated film flow to be the dominant flow regime with the vapor core sandwiched between thin liquid layers. Dryout periodically appeared in the proximity of the contact points, and these dry areas became more stable and smaller as the quality increased.

\section{Conflict of interests}

None declared.

\section{Acknowledgments}

The authors of the present work would like to thank ONR (Office of Naval Research) and in particular Dr. Mark Spector (grant monitor at ONR) for the financial support of the present project under the award numbers N000141210340 and N000141210398. The authors would also like to thank the collaboration between PCHTL (Phase Change Heat Transfer Laboratory) at UMD and LTCM (Laboratory of Heat and Mass Transfer) at EPFL for sharing experiences, knowledges and experimental data.

\section{References}

[1] Z.H. Ayub, Plate Heat Exchanger Literature Survey and New Heat Transfer and Pressure Drop Correlations for Refrigerant Evaporators, Heat Transf. Eng. 24 (2003) 3-16. doi:10.1080/01457630390218074.

[2] R.M. Manglik, L. Wang, B. Sunden, Plate Heat Exchangers: Design, Applications and Performance, WIT Press, Southampton, 2007. 
[3] T. Khan, M. Khan, M.-C. Chyu, Z. Ayub, J. Chattha, Review of Heat Transfer and Pressure Drop Correlations for Evaporation of Fluid Flow in Plate Heat Exchangers (RP1352), HVAC\&R Res. 15 (2009) 169-188. doi:10.1080/10789669.2009.10390832.

[4] M.M. Abu-Khader, Plate heat exchangers: Recent advances, Renew. Sustain. Energy Rev. 16 (2012) 1883-1891. doi:10.1016/j.rser.2012.01.009.

[5] G. Gaiser, V. Kottke, Flow phenomena and local heat and mass transfer in corrugated passages, Chem. Eng. Technol. - CET. 12 (1989) 400-405. doi:10.1002/ceat.270120157.

[6] J. Stasiek, M.W. Collins, M. Ciofalo, P.E. Chew, Investigation corrugated of flow and heat transfer in Experimental results, Int. J. Heat Mass Transf. 39 (1996) 149-164.

[7] S. Freund, S. Kabelac, Investigation of local heat transfer coefficients in plate heat exchangers with temperature oscillation IR thermography and CFD, Int. J. Heat Mass Transf. 53 (2010) 3764-3781. doi:10.1016/j.ijheatmasstransfer.2010.04.027.

[8] E. Djordjevic, S. Kabelac, Flow boiling of R134a and ammonia in a plate heat exchanger, Int. J. Heat Mass Transf. 51 (2008) 6235-6242. doi:10.1016/j.ijheatmasstransfer.2008.01.042.

[9] D. Steiner, J. Taborek, Flow boiling heat transfer in vertical tubes correlated by an asymptotic model, Heat Transf. Eng. 13 (1992) 43-69.

[10] G.N. Danilova, V.M. Azarskov, B.B. Zemskov, Danilova Teploobmen v plastinchatihisparitljan razichnole geometri, Kholod. Tek. 4 (1981) 25-31.

[11] F. Vakili-Farahani, R.L. Amalfi, J.R. Thome, Two-Phase Flow and boiling of R-245fa in a $1 \mathrm{~mm}$ pressing depth plate heat exchanger - Part I : Adiabatic pressure Drop, Interfacial Phenom. Heat Transf. 2 (2014) 325-342.

[12] F. Vakili-Farahani, R.L. Amalfi, J.R. Thome, Two-Phase Flow and boiling of R-245fa in a $1 \mathrm{~mm}$ pressing depth plate heat exchanger - Part II : Flow boiling heat transfer, Interfacial Phenom. Heat Transf. 2 (2014) 343-361. 
[13] R.L. Amalfi, F. Vakili-Farahani, J.R. Thome, Flow boiling and frictional pressure gradients in plate heat exchangers: part 1, review and experimental database, Int. J. Refrig. (2015). doi:10.1016/j.ijrefrig.2015.07.010.

[14] R.L. Amalfi, F. Vakili-Farahani, J.R. Thome, Flow boiling and frictional pressure gradients in plate heat exchangers: part 2, comparison of literature methods to database and new prediction methods, Int. J. Refrig. (2015). doi:10.1016/j.ijrefrig.2015.07.009.

[15] M. Gradeck, M. Lebouché, Two-phase gas-liquid flow in horizontal corrugated channels, Int. J. Multiph. Flow. 26 (2000) 435-443. doi:10.1016/S0301-9322(99)00018-X.

[16] C. Tribbe, H.M. Müller-Steinhagen, Gas/Liquid Flow in Plate-and-Frame Heat Exchangers - Part I: Pressure Drop Measurements, Heat Transf. Eng. 22 (2001) 5-11. doi:10.1080/01457630150215677.

[17] C. Tribbe, H.M. Müller-Steinhagen, Gas/Liquid Flow in Plate-and-Frame Heat Exchangers - Part II: Two-Phase Multiplier and Flow Pattern Analysis, Heat Transf. Eng. 22 (2001) 12-21. doi:10.1080/01457630150215686.

[18] P. Vlasogiannis, G. Karagiannis, P. Argyropoulos, V. Bontozoglou, Air-water two-phase flow and heat transfer in a plate heat exchanger, Int. J. Multiph. Flow. 28 (2002) 757-772. doi:10.1016/S0301-9322(02)00010-1.

[19] Y.Y. Hsieh, L.J. Chiang, T.-F. Lin, Subcooled flow boiling heat transfer of R-134a and the associated bubble characteristics in a vertical plate heat exchanger, Int. J. Heat Mass Transf. 45 (2002) 1791-1806. doi:10.1016/S0017-9310(01)00294-0.

[20] H. Asano, N. Takenaka, T. Fujii, N. Maeda, Visualization and void fraction measurement of gas-liquid two-phase flow in plate heat exchanger., Appl. Radiat. Isot. 61 (2004) 707713. doi:10.1016/j.apradiso.2004.03.098.

[21] K. Nilpueng, S. Wongwises, Two-phase gas-liquid flow characteristics inside a plate heat exchanger, Exp. Therm. Fluid Sci. 34 (2010) 1217-1229. doi:10.1016/j.expthermflusci.2010.05.001. 
[22] V. Solotych, J. Kim, S. Dessiatoun, Local Heat Transfer Measurements Within a Representative Plate Heat Exchanger Geometry Using Infrared (IR) Thermography, J. Enhanc. Heat Transf. 22 (2015).

[23] J.R. Taylor, Error Analysis, University Science Books, Sausalito, 1982.

[24] B. Thonon, R. Vidil, C. Marvillet, Recent research and developments in plate heat exchangers, J. Enhanc. Heat Transf. 2 (1995) 149-155.

[25] R. Heavner, Performance of an industrial plate heat exchanger: effect of chevron angle, AIChE Symp. Ser. 89 (1993) 262-267.

[26] H. Kumar, The Plate Heat Exchanger: Construction and Design, Inst. Chem. Eng. Symp. Ser. 86 (1984) 1275-1288.

[27] A. Muley, R.M. Manglik, H.M. Metwally, Enhanced heat transfer characteristics of viscous liquid flows in a chevron plate heat exchanger, J. Heat Transfer. 121 (1999) 10111017.

[28] W.W. Focke, P.G. Knibbe, Flow visualization in parallel plate ducts with corrugated walls.pdf, J. Fluid Mech. (1986).

[29] T.S. Khan, M.S. Khan, M.C. Chyu, Z.H. Ayub, Experimental investigation of evaporation heat transfer and pressure drop of ammonia in a 60 chevron plate heat exchanger, Int. J. Refrig. 35 (2012) 336-348. doi:10.1016/j.ijrefrig.2011.10.018.

[30] M.S. Khan, T.S. Khan, M.C. Chyu, Z.H. Ayub, Experimental investigation of evaporation heat transfer and pressure drop of ammonia in a 30 chevron plate heat exchanger, Int. J. Refrig. 35 (2012) 1757-1765. doi:10.1016/j.ijrefrig.2012.05.019.

[31] M.S. Khan, T.S. Khan, M.-C. Chyu, Z.H. Ayub, Evaporation heat transfer and pressure drop of ammonia in a mixed configuration chevron plate heat exchanger, Int. J. Refrig. 41 (2014) 92-102. doi:10.1016/j.ijrefrig.2013.12.015. 
[32] E. Lee, H. Kang, Y. Kim, Flow boiling heat transfer and pressure drop of water in a plate heat exchanger with corrugated channels at low mass flux conditions, Int. J. Heat Mass Transf. 77 (2014) 37-45. doi:10.1016/j.ijheatmasstransfer.2014.05.019.

[33] T.S. Khan, M.S. Khan, M.-C. Chyu, Z.H. Ayub, Ammonia evaporation in a mixed configuration chevron plate heat exchanger with and without miscible oil, Int. J. Refrig. 51 (2015) 120-134. doi:10.1016/j.ijrefrig.2014.12.002.

[34] T.H. Kim, E. Kommer, S. Dessiatoun, J. Kim, Measurement of two-phase flow and heat transfer parameters using infrared thermometry, Int. J. Multiph. Flow. 40 (2012) 56-67. doi:10.1016/j.ijmultiphaseflow.2011.11.012.

[35] V.D. Donowski, S.G. Kandlikar, Correlating Evaporation Heat Transfer Coefficient of Refrigerant R-134a in a Plate Heat Exchanger, Paper 154, Alaska, 2000.

[36] Y.Y. Hsieh, T.-F. Lin, Evaporation Heat Transfer and Pressure Drop of Refrigerant R410a Flow in a Vertical Plate Heat Exchanger, J. Heat Transfer. 125 (2003) 852-857.

[37] D.H. Han, K.J. Lee, Y.H. Kim, Experiments on the characteristics of evaporation of R410A in brazed plate heat exchangers with different geometric configurations, Appl. Therm. Eng. 23 (2003) 1209-1225. doi:10.1016/S1359-4311(03)00061-9. 